\title{
Pathway for enhanced recovery after spinal surgery-a systematic review of evidence for use of individual components
}

\author{
Ana Licina ${ }^{*^{*}} \mathbb{D}$, Andrew Silvers ${ }^{2}$, Harry Laughlin ${ }^{3}$, Jeremy Russell ${ }^{4}$ and Crispin Wan ${ }^{3,5}$
}

\begin{abstract}
Background: Enhanced recovery in spinal surgery (ERSS) has shown promising improvements in clinical and economical outcomes. We have proposed an ERSS pathway based on available evidence. We aimed to delineate the clinical efficacy of individual pathway components in ERSS through a systematic narrative review.

Methods: We included systematic reviews and meta-analysis, randomized controlled trials, non-randomized controlled studies, and observational studies in adults and pediatric patients evaluating any one of the 22 predefined components. Our primary outcomes included all-cause mortality, morbidity outcomes (e.g., pulmonary, cardiac, renal, surgical complications), patient-reported outcomes and experiences (e.g., pain, quality of care experience), and health services outcomes (e.g., length of stay and costs). Following databases (1990 onwards) were searched: MEDLINE, EMBASE, and Cochrane Library (Cochrane Database of Systematic Reviews and CENTRAL). Two authors screened the citations, full-text articles, and extracted data. A narrative synthesis was provided. We constructed Evidence Profile (EP) tables for each component of the pathway, where appropriate information was available. Due to clinical and methodological heterogeneity, we did not conduct a meta-analyses. GRADE system was used to classify confidence in cumulative evidence for each component of the pathway.
\end{abstract}

Results: We identified 5423 relevant studies excluding duplicates as relating to the 22 pre-defined components of enhanced recovery in spinal surgery. We included 664 studies in the systematic review. We identified specific evidence within the context of spinal surgery for $14 / 22$ proposed components. Evidence was summarized in EP tables where suitable. We performed thematic synthesis without EP for $6 / 22$ elements. We identified appropriate societal guidelines for the remainder of the components.

Conclusions: We identified the following components with high quality of evidence as per GRADE system: preemptive analgesia, peri-operative blood conservation (antifibrinolytic use), surgical site preparation and antibiotic prophylaxis. There was moderate level of evidence for implementation of prehabilitation, minimally invasive surgery, multimodal perioperative analgesia, intravenous lignocaine and ketamine use as well as early mobilization. This review allows for the first formalized evidence-based unified protocol in the field of ERSS.

Further studies validating the multimodal ERSS framework are essential to guide the future evolution of care in patients undergoing spinal surgery.

Keywords: Enhanced recovery after spinal surgery (ERSS), Perioperative pathway, Perioperative outcomes, Systematic review;

\footnotetext{
* Correspondence: analicina@hotmail.com

${ }^{1}$ Austin Health, 145 Studley Road, Heidelberg, Victoria 3084, Australia

Full list of author information is available at the end of the article
}

\section{$\triangle B M C$}

(c) The Author(s). 2021 Open Access This article is licensed under a Creative Commons Attribution 4.0 International License, which permits use, sharing, adaptation, distribution and reproduction in any medium or format, as long as you give appropriate credit to the original author(s) and the source, provide a link to the Creative Commons licence, and indicate if changes were made. The images or other third party material in this article are included in the article's Creative Commons licence, unless indicated otherwise in a credit line to the material. If material is not included in the article's Creative Commons licence and your intended use is not permitted by statutory regulation or exceeds the permitted use, you will need to obtain permission directly from the copyright holder. To view a copy of this licence, visit http://creativecommons.org/licenses/by/4.0/ The Creative Commons Public Domain Dedication waiver (http://creativecommons.org/publicdomain/zero/1.0/) applies to the data made available in this article, unless otherwise stated in a credit line to the data. 


\section{Background}

Enhanced recovery after surgery (ERAS) programs have demonstrated improvements in outcomes. Improvements have been demonstrated in recovery, functional measures, lower morbidity, decreased length of stay with healthcare cost savings $[1,2]$. The disease burden of spinal pathologies is high [3]. Between 2004 to 2015, there has been an increase in volume of elective lumbar fusion accompanied by increased hospital costs [4]. Limited enhanced recovery pathways have been applied to spinal surgery. A consistent feature is a uniform finding of decreased length of stay [5-8]. There was a notable decrease in the adverse events during hospital stay $[8,9]$.

There is a need to apply lessons learned from enhanced recovery programs in other surgical specialties to surgery of the spine [10]. Prior narrative qualitative reviews have delineated recommendations for the incorporation of individual components into an enhanced recovery after spinal surgery (ERSS) program. Several critical components of enhanced recovery in spinal surgery have been identified. These include: provision of comprehensive perioperative nutrition, multimodal analgesia, minimally invasive surgery where clinically feasible and early mobilization $[10$, 11]. Individual ERSS programs differ substantially [12]. Our group of authors have identified and proposed the first comprehensive program of Enhanced Recovery in Spinal Surgery (Table 1), [11]. We defined the individual components based on the enhanced recovery protocols in other surgical subspecialties and prior qualitative reviews of ERAS in spinal surgery $[1,12-20]$. .

The aim of this study was to systematically evaluate pre-defined individual components of an ERSS pathway (program). We planed to create an evidence-based assessment of the available literature for each pre-defined component of an ERSS program [21]. Formulating the evidence base for each component, would strengthen the quality of ERSS programs. Consistency with regards to best practice in ERSS, would allow for standardization of care pathways. Greater standardization of care pathways results in improved external validity across comparative research.

\section{Methods}

This systematic review has been performed according the methodological standards for complex reviews [2229]. Our findings have been reported according to the standards for the Preferred Reporting Items for Systematic Reviews and Meta-Analysis [30] (supplementary file 1). Protocol for this review was prospectively registered with the International Register of Systematic Reviews identification number CRD42019135289 [31]. The authors identified the essential components of enhanced recovery within the area of spinal surgery. The authors performed this process by reviewing the current enhanced recovery protocols as recommended by the ERAS Society. We identified and applied the relevant

Table 1 Components of enhanced recovery in spinal surgery, grouped according to perioperative stage of care.

\begin{tabular}{lll}
\hline Preadmission period & Intraoperative period & Postoperative period \\
\hline $\begin{array}{ll}\text { 1. Preadmission information, education and } \\
\text { counseling }\end{array}$ & 9. Prevention of nausea and vomiting & 17. Thromboprophylaxis \\
$\begin{array}{ll}\text { 2. Risk assessment, preoperative optimization, } \\
\text { including lifestyle factor modification }\end{array}$ & $\begin{array}{l}\text { 10. Surgical site preparation and antimicrobial prophylaxis } \\
\text { 10.1 Surgical site preparation }\end{array}$ & 18. Urinary drainage \\
2.1 Pre-operative risk stratification & 10.2 Antimicrobial prophylaxis & 19. Postoperative nutrition and \\
& 11. Local anaesthetic infiltration & 20. Postoperative glycemic \\
2.2 Preoperative assessment and optimization & 12. Standard anaesthetic protocol & control \\
2.3 Alcohol use & 13.Surgical access (open and minimally invasive spinal & 21. Early mobilization \\
2.4 Tobacco use & surgery, including robotic surgery) & Quality of care measures \\
3. Prehabilitation & 14. Maintenance of normothermia & 22. Audit \\
4. Preoperative nutritional care & 15. Intraoperative fluid and electrolyte therapy & \\
4.1 Nutritional assessment and screening & 16. Perioperative analgesia & \\
4.2 Perioperative immuno-nutrition & & \\
5. Management of anaemia & & \\
6. Perioperative blood conservation strategies & & \\
Preoperative period & & \\
7.Preoperative fasting and carbohydrate loading & & \\
8.Preemptive analgesia & &
\end{tabular}


components to the field of spinal surgery $[1,10,12-15$, 32]. We have published this work through a peer reviewed protocol dissemination [11].

\section{Eligibility criteria}

Our patient population included adult and paediatric patients undergoing spinal surgical procedure on any spinal anatomical site. These anatomical sites cervical (anterior or posterior cervical decompression and fusion), thoracic (e.g., thoracic decompression and fusion), lumbar (e.g., lumbar decompression and fusion, lumbar laminectomy, sacral or any one combination of these). The interventions of interest have been classified in 5 perioperative pillars: preadmission period, preoperative period, intraoperative period, postoperative period, and audit and compliance processes (Table 1). These interventions (22 individual pathway components) have been defined through previous published work [11]. We reviewed the evidence with regards to each component studied independently or in any one combination [33]. Comparator interventions consisted of standard of care, no treatment or placebo.

In line with other ERAS reviews, we defined our primary outcomes in the following groups [12, 34]:

- Morbidity, including pulmonary, cardiac, and renal complication rates; surgical complication rates; and

- readmission rates.

- Mortality from all causes.

- Patient-reported experiences and outcomes (PREMs/PROMs), including pain-related outcomes.

- (pain score rating and/or opioid consumption, pain management satisfaction), readiness for surgery, quality of care patient scores, and quality of recovery outcomes.

- Health service-related outcomes, including length of stay and reported economic/financial outcomes (e.g., costs of the length of stay).

We included systematic reviews and meta-analysis, randomized controlled trials, non-randomized controlled studies, and observational studies (e.g., cohort studies, case-control studies, cross-sectional studies, and case series). We included human data studies published in the English language after 1990. The Preferred Reporting Items for Systematic Reviews and Meta-Analyses of Complex Interventions series lays out PICOTS framework for systematic reviews of complex interventions [35].

Our full review eligibility criteria are listed in Table 2.

\section{Information sources and literature searches}

The following electronic databases (from 1990 onwards) were searched: MEDLINE via Ovid SP; EMBASE via.
Ovid SP; and Cochrane Library (Cochrane Database of Systematic Reviews and CENTRAL). We searched the grey literature through the available search engines: Google Scholar, OpenGrey and GreyNet [36-38]. We initiated the original search for studies in January 2020 and updated it in May 2020. For the search strategy, we combined keyword(s) and subject headings for all literature types in the pre-determined databases [29]. Keywords were related to spine surgery, enhanced recovery, pre-operative care, intra-operative care, post-operative care, analgesia, mobilization, fluids. The specific details are contained within the supplementary files (supplementary file 2). We handled study overlap by tracking the index primary studies. For some selected pre-defined pathway components, there was a paucity of identified studies as pertaining to spinal surgery. Under those circumstances, we sought to identify large studies, metaanalysis or societal recommendations of best practice.

\section{Data extraction, management, analysis and presentation}

Standardized data parameters were extracted from each study. These parameters included: publication details, study characteristics, participant characteristics, type of spinal surgery, intervention and comparator characteristics, and outcomes. The results of the data search were presented in a PRISMA flow diagram indicating the number of studies retrieved, screened and excluded as per exclusion criteria (see Fig. 1). We have presented our findings according to each individual predetermined element of the multimodal enhanced recovery pathway (Table 1). One author extracted appropriate information from randomized controlled trials on the methodological quality of studies. This information included random sequence generation, allocation concealment, blinding of participants and personnel, blinding of outcome assessment, incomplete outcome data, selective outcome reporting, and other bias [39, 40]. For non- randomized studies data extraction on random sequence generation and allocation concealment was not applicable.

\section{Risk of Bias and thematic synthesis}

Risk of bias in randomized controlled studies was assessed using the Cochrane Risk of Bias tool [40]. ROBINS-I (Risk of Bias in Non-randomized Studies of Interventions) tool was used to evaluate the risk of bias in non-randomized studies [41]. We used the revised AMSTAR-2 tool to assess the risk of bias in systematic reviews [42]. We used the GRADE system (Grading of Recommendations, Assessment, Development and Evaluation) system to classify the evidence into one of four categories: high, moderate, low, and very low [43, 44]. Evidence based on randomized controlled trials was considered as high quality unless confidence in the evidence was decreased due to study limitations, 
Table 2 Review eligibility criteria including the extended PICOTS framework for reviews of complex interventions

\begin{tabular}{|c|c|c|}
\hline $\begin{array}{l}\text { Study } \\
\text { characteristic }\end{array}$ & Inclusion criteria & Exclusion criteria \\
\hline $\begin{array}{l}\text { Patient } \\
\text { population (P) }\end{array}$ & $\begin{array}{l}\text { Adults undergoing spinal surgical procedures; } \\
\text { Paediatric population undergoing spinal surgical procedures; }\end{array}$ & $\begin{array}{l}\text { Patients undergoing non-surgical management } \\
\text { of spinal conditions; } \\
\text { Spinal trauma patients; }\end{array}$ \\
\hline $\begin{array}{l}\text { Intervention- } \\
\text { treatment(I) }\end{array}$ & $\begin{array}{l}\text { Twenty-two pre-defined components of an ERSS pathway (as outlined in Table 1) } \\
\text { alone or in combination with another component; } \\
\text { Other proposed ERSS pathways incorporating one or more pre-defined interven- } \\
\text { tions will be included; }\end{array}$ & \\
\hline Comparator(C) & Standard of care, no treatment or placebo; & \\
\hline Outcomes(0) & $\begin{array}{l}\text {-Mortality from all causes; } \\
\text {-Morbidity including: pulmonary, cardiac and renal complication rates, surgical } \\
\text { complication rates (including readmissions); } \\
\text {-Patient reported experiences and outcomes (PROMs/PREMS): pain-related out- } \\
\text { comes (e.g. pain score rating, pain management satisfaction), quality of care (readi- } \\
\text { ness for surgery, quality of care patient scores, quality of recovery after surgery); } \\
\text {-Health service-related outcomes: length of stay (in hospital, in ICU)and economic/ } \\
\text { financial outcome; }\end{array}$ & \\
\hline Timing & $\begin{array}{l}\text { Perioperative process-preadmission, preoperative, intraoperative and postoperative } \\
\text { setting; }\end{array}$ & $\begin{array}{l}\text { Studies incorporating long-term (greater than } 3 \\
\text { months) postoperative rehabilitation; }\end{array}$ \\
\hline Study design & $\begin{array}{l}\text { Systematic reviews, meta-analysis } \\
\text { Randomized controlled trials } \\
\text { Non-randomized studies } \\
\text { Observational studies (cohort studies, case-control studies, cross-sectional studies, } \\
\text { case series); }\end{array}$ & Case reports; \\
\hline Study setting & $\begin{array}{l}\text { Inpatient care (including patients whose condition requires admission to a hospital } \\
\text { same day discharge surgical); }\end{array}$ & $\begin{array}{l}\text { Outpatient clinics, medical and non-surgical } \\
\text { management of spinal conditions; }\end{array}$ \\
\hline
\end{tabular}

inconsistency of results, indirectness of evidence, imprecision, and reporting biases. Observational studies were considered low quality; however, they were graded higher if the treatment effect observed is very large or if there is evidence of a dose-response relationship [33, 44, 45].

Endpoint of the GRADE evidence summary consists of Evidence Profile (EP) tables across individual pathway components [43]. Risk of bias across outcomes for individual pathway components was presented in Evidence Profile Tables (supplementary file 3 ). We performed a thematic synthesis and narrative analysis for each proposed component [27]. Forest plots were generated for the following components: anaesthetic protocol, use of multimodal analgesia and intravenous lignocaine infusion (supplementary file 5). In line with our planned protocol, quantitative data synthesis was not attempted due to the inherent heterogeneity of the studies. This method of evidence synthesis is in line with other published enhanced recovery reviews $[1,13,15,17,18,46$, 47]. We did not make recommendations on the utility of pathway components, in line with recommended practice for systematic reviews [48].

\section{Results}

Our search strategy retrieved a total of 5423 studies excluding duplicates using 22 different searches for the each relevant ERSS item as outlined in Table 1. During the review of full text articles, we excluded studies which did not pertain to the topic studied (surgery of the spine), which did not describe the intervention in sufficient detail or published articles which were not methodologically suited (case reports, opinions, comments, narrative reviews). Where studies were not available pertaining to pre-defined pathway component of spinal surgery, databases and grey literature were reviewed as relating to societal recommendations and major pertinent studies for perioperative patient management. This methodology yielded 148 further studies for inclusion. We included 664 studies in the final review. The results of our search have been presented in Fig. 1, PRISMA Diagram. We have grouped the evidence base according to the component of the pathway.

Evidence Profile tables were generated when a number of studies were identified investigating an intervention for one of the predetermined outcomes. We have generated Evidence Profile tables for the following pathway components: 2.4 Tobacco use, 3.Prehabilitation, 4.1Preoperative nutritional screening, 5.Management of anemia, 6.Peri-operative blood conservation strategies, 12. Standard anaesthetic protocol, 16. Perioperative analgesia including use of intravenous lignocaine and 21.Mobilization.

For the following elements we identified published meta-analysis: 6.Peri-operative blood conservation strategies, use of tranexamic acid, 8. Pre-emptive analgesia, 


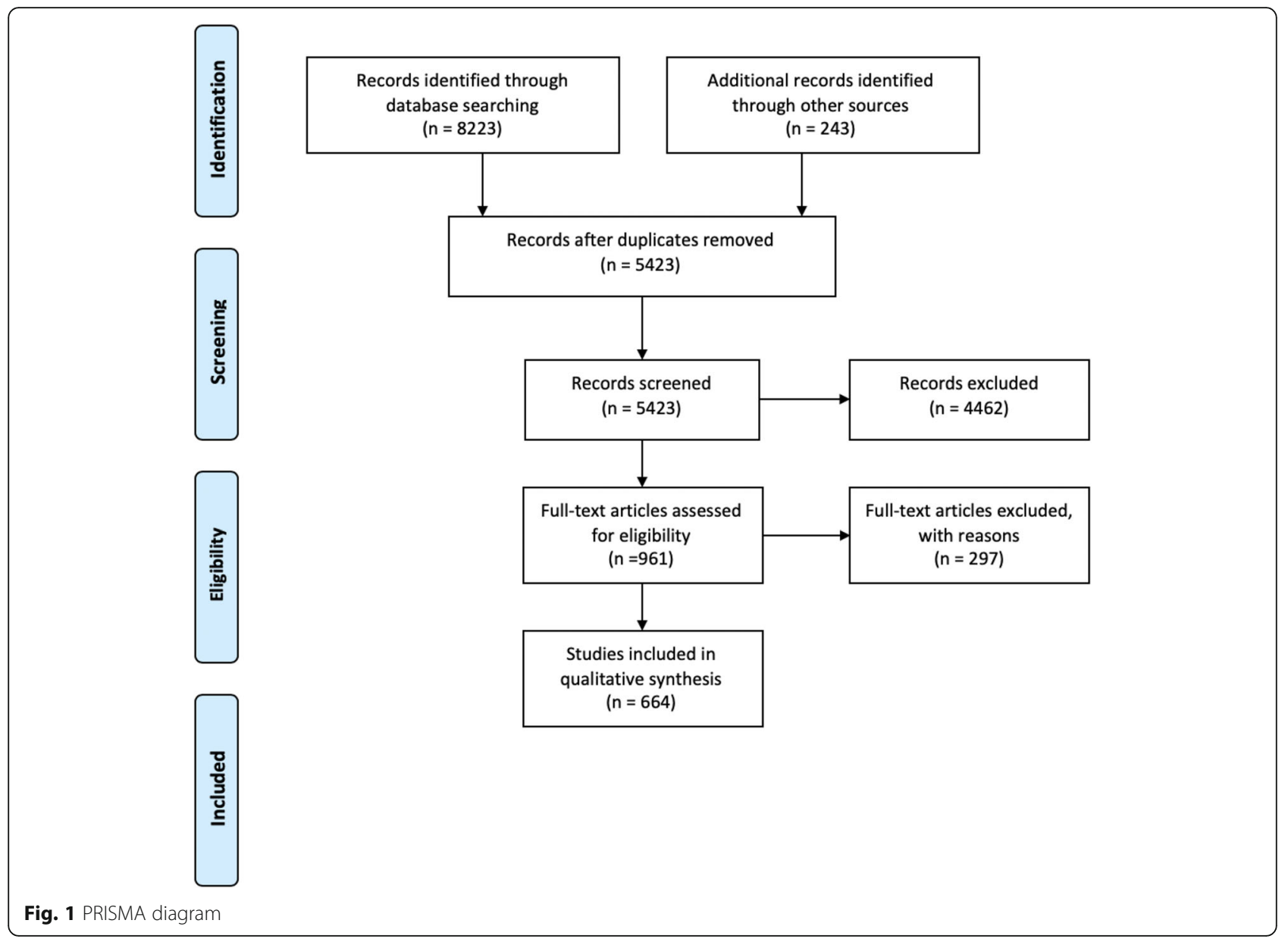

10.2 Antimicrobial prophylaxis, 11. Local anaesthetic infiltration, 13. Surgical access (open and minimally invasive spinal surgery), 16 . Perioperative analgesia including use of NSAIDS, ketamine, gabapentinoids and intrathecal morphine and 17. Thromboprophylaxis. We incorporated the relevant meta-analysis findings into each pathway.

We were able to identify heterogenous studies pertaining to surgery of the spine for the following components: 10.1 Surgical site preparation,14. Maintenance of normothermia, 15. Intra-operative fluid and electrolyte therapy, 18. Urinary drainage, 19. Post-operative nutrition and fluid management and 20.Post-operative glycemic control. For these components, we were unable to construct evidence profile tables. As such, we performed a thematic synthesis of evidence.

Due to the paucity of evidence pertaining to spinal surgery, we identified societal recommendations for the following components: 1.Preadmission information, Risk assessment (2.1 Preoperative risk stratification, 2.2 Preoperative optimization and 2.3 Alcohol use), 4.2 Perioperative immuno-nutrition, 7. Pre-operative fasting and carbohydrate loading, 9. Prevention of post-operative nausea and vomiting and 22. Audit.

\section{Presentation}

We have presented our findings according to each individual element of the multimodal enhanced recovery pathway in line with other subspecialty ERAS pathways $[13,14,49]$. Please see Table 3 and supplementary file 4.

\section{Discussion}

\section{Preadmission period}

The preadmission period is an opportunity for patient education, assessment of comorbidities, risk stratification and optimization of modifiable patient-related factors.

\section{Preadmission information, education and counseling}

Patient information provision has long been considered a key element of enhanced recovery pathways [50, 51]. Patient perioperative experience and the psychological aspect may be improved with pre-admission counseling [52-55]. Psychopathology and patient expectations have been linked to poor results in spinal surgery with 
Table 3. Summary of the findings for clinical care

\section{ERSS Element \\ Summary of findings for clinical care}

1.Preadmission information, education and counseling

Preadmission information, education and counseling may have a positive impact on subjective perioperative patient experience. Studies do not show any evidence of harm;

2.Risk assessment, preoperative optimization, including lifestyle factor modification

2.1 Preoperative risk stratification

Preoperative risk assessment tools tests can be used to identify patients at risk of complications; Prognostic accuracy and predictive ability of a risk measurement tool should be considered;

2.2 Preoperative assessment and optimization

Preoperative assessment and optimization of modifiable comorbidities should be performed on all patients. Although the degree to which preoperative optimization affects healthcare outcomes is unclear, it is intuitive that any modifiable co-morbidities should be optimized using the preoperative process

2.3 Alcohol use

Increased alcohol consumption has been shown to be associated with increased perioperative morbidity. For alcohol abusers, 1 month of abstinence before surgery is beneficial;

2.4 Tobacco use

For tobacco users, 1 month of abstinence before surgery decreases the risk of infection and wound healing;

3.Prehabilitation

Multimodal prehabilitation may improve patient reported outcome measures and allow for earlier hospital discharge in spinal surgery;

4. Preoperative Nutritional Care

4.1. Nutritional Assessment and Screening

4.2 Immuno-nutrition

5. Management of anaemia

6. Perioperative blood conservation strategies

7.Preoperative fasting and carbohydrate loading

Risk assessment and screening of nutritional status should be performed in patients undergoing spinal surgery;

There have been no benefits of immuno-nutrition in spinal surgery;

Clinically guided use of intravenous or oral iron, vitamin B12, folic acid or erythropoietin for patients suffering from anaemia and/or low iron stores should be implemented in patients undergoing moderate and major spinal surgery;

Tranexamic acid used at the higher dosage is effective in decreasing intraoperative blood loss. Cell saver techniques should be used in adolescents undergoing major corrective surgery. Cellsaver techniques may be beneficial when major blood loss is anticipated in adults.

In patients without delayed gastric emptying standard societal fasting implementations can be made;

8. Pre-emptive analgesia

Multimodal pre-emptive analgesia utilizing individual gabapentinoids and non-steroidal antiinflammatory agents improves pain scores and functional measures in the immediate postoperative period;

9. Prevention of postoperative nausea and vomiting

Risk assessment of patients according to the anaesthetic and procedural factors is recommended. Step- wise non-pharmacological and pharmacological PONV prophylaxis according to the guidelines is recommended. Use of anaesthetic techniques which minimize risk of PONV in high-risk patients should be considered;

10. Surgical site preparation and antimicrobial prophylaxis

10.1 Surgical site preparation

10.2 Antimicrobial prophylaxis

11.Local anaesthetic infiltration

12. Standard Anaesthetic protocol

13. Surgical access- open and minimally invasive spinal surgery

14. Maintain normothermia

15. Intraoperative fluid and electrolyte therapy

16. Peri-operative analgesia
Chlorhexidine gluconate $(\mathrm{CHG})$ is more effective at reducing the pre-operative viable bacterial load than povidone. Alcohol based agents are superior to aqueous solutions;

Routine prophylaxis with cefazolin within $1 \mathrm{~h}$ prior to skin incision is recommended. Patients with MRSA should be treated prophylactically with vancomycin initiated $1 \mathrm{~h}$ prior to skin incision;

Local anaesthetic wound infiltration in major spinal surgery has some immediate benefit on postoperative pain scores;

Total intravenous anaesthesia utilizing propofol demonstrates improved post-operative recovery markers after surgery. Higher total doses of intra-operative remifentanil are likely to result in the phenomena of acute opioid tolerance and hyperalgesia;

Minimally invasive surgical approaches improve pain scores, decrease opioid consumption and decrease length of stay, when used within the appropriate clinical context;

Measures to maintain normothermia and avoid hyperthermia should be implemented in spinal surgical patients;

Goal-directed intraoperative fluid management should be implemented using contextually appropriate indicators and measurements of cardiac output in patients undergoing moderate/ major surgery of the spine;

Simple analgesics such as acetaminophen and NSAIDs are safe and efficacious, particularly in 
Table 3. Summary of the findings for clinical care (Continued)

\begin{tabular}{|c|c|}
\hline ERSS Element & Summary of findings for clinical care \\
\hline & $\begin{array}{l}\text { combination. Ketamine in both intraoperative and post-operative form reduces pain scores. } \\
\text { Consideration should be given to pre-emptive gabapentinoid administration; Intravenous ligno- } \\
\text { caine has been shown to have immediate and long-term benefits for analgesia and function; }\end{array}$ \\
\hline 17. Thromboprophylaxis & $\begin{array}{l}\text { Patients undergoing spinal surgery should have mechanical thromboprophylaxis by well-fitting } \\
\text { compression stockings and/or intermittent pneumatic compression until discharge. There is a } \\
\text { role for careful use of chemoprophylaxis; }\end{array}$ \\
\hline 18. Urinary drainage & Urinary catheters should be removed as soon as feasible; \\
\hline $\begin{array}{l}\text { 19. Post-operative nutrition and fluid } \\
\text { management }\end{array}$ & $\begin{array}{l}\text { Patients should be encouraged to transition as early as tolerated to oral intake. Postoperative } \\
\text { fluid replacement should be carefully guided by patient intake and ongoing fluid losses; }\end{array}$ \\
\hline 20. Post-operative glycemic control & $\begin{array}{l}\text { Maintain conventional blood glucose target in the postoperative period in patients undergoing } \\
\text { spinal surgery; }\end{array}$ \\
\hline 21. Early mobilization & $\begin{array}{l}\text { Patients should be mobilized actively on the day of surgery as permitted by the clinical } \\
\text { condition; Patients should be encouraged to mobilize actively from the morning of the first } \\
\text { postoperative day; }\end{array}$ \\
\hline 22.Audit & Audit of compliance and care outcomes should be performed regularly in ERSS programs; \\
\hline
\end{tabular}

increased pain and decreased function. This has led to an increased reliance on pre-surgical psychological screening (PPS) as part of the surgical diagnostic process in spinal surgery [55-58].

Studies do not show any evidence of harm from preoperative information provision or psychological intervention. There may be utility from information provision, balanced against no known harmful effects. There is limited evidence available pertaining to the intervention specifically in patients undergoing surgery of the spine.

\section{Risk assessment, preoperative assessment, optimization and lifestyle factor modification}

2.1. Pre-operative risk stratification Perioperative period offers an opportunity for risk stratification [59]. Nearly $80 \%$ of patient deaths come from the high-risk patient group [60]. In a major retrospective study in the USA, it was found occurrence of a major complication within 30 days of surgery was associated with reduced median survival by $69 \%$ at 8 years [61]. Multiple diverse risk scoring systems are currently in use for major surgery, including spinal surgery. Assessing cardiovascular risk can be undertaken whilst utilizing ACC/AHA guidelines on perioperative cardiovascular evaluation and care for non-cardiac surgery [62]. Lee's cardiac risk index, Revised Cardiac Risk Index (RCRI), POSSUM (Physiological and Operative Severity Scoring for the enumeration of Mortality and morbidity), the Portsmouth POSSUM (P-POSSUM) and Duke Activity Status Index (DASI) scores have been validated for patients undergoing major non-cardiac surgery [63-66].

The American College of Surgeons National Surgical Quality Improvement Program (ACS NSQIP) has been deemed to have high internal validity although external validation has been inconsistent $[67,68]$. A retrospective cohort study of the NSQIP database consisting of patients who had undergone elective posterior lumbar fusion was undertaken. The variables associated with greater risk and extended length of stay included increasing age, morbid obesity, operative time, multilevel procedure and intraoperative transfusion [69]. In a retrospective review of NSQIP database, patients undergoing elective spinal surgery had the expected risk factors for cardiovascular complications consistent with those demonstrated by the Revised Cardiac Risk Index [70]. Individual preoperative risk assessment tools tests can be used to identify patients at risk of complications and perform a risk-based stratification. There is moderate quality evidence in support individualized risk stratification utilizing the most suitable risk-stratification assessment tool.

2.2. Preoperative assessment and optimization Patient preoperative assessment allows for an opportunity for examination of comorbidities with subsequent identification of fixed and optimization of modifiable conditions [15-75]. Obese patients having spinal surgery were found to have increased blood loss, prolonged hospital stay and were more likely to develop infection $[76,77]$. Patients with diabetes were found to have greater disability and more likely to have failed spinal fusion as compared to patients without diabetes [78-80]. Frailty is an emerging risk assessment tool, requiring further studies [81]. The degree to which preoperative optimization and modification of multimorbidity, affects healthcare outcomes is unclear [59, 81]. Modifiable co-morbidities should be optimized using the preoperative process. Evidence base is of low quality due to a limited number of heterogenous studies. 
2.3. Alcohol use Postoperative morbidity is increased by two- to threefold in alcohol abusers [82]. Preoperative alcohol consumption is associated with an increased risk of postoperative morbidity, general infections, wound complications, pulmonary complications, prolonged stay at the hospital, and admission to intensive care unit [83]. In a subset of patients without clinical or historical evidence of alcohol-related illness, 1 month of preoperative abstinence has been shown to significantly improve outcome [83-85].

Significant alcohol consumption has been shown to be associated with increased perioperative morbidity. For alcohol abusers, 1 month of abstinence before surgery is beneficial. Evidence is considered to be of moderate quality due to heterogenous endpoints in available studies.

2.4. Tobacco use Smoking is an independent risk factor for non-union in spinal fusion procedures [86-89]. Postoperative infection and wound complications are significantly increased by tobacco consumption [88]. Decreased risk of infection, perioperative respiratory problems, and wound complications have been demonstrated 1 month after cessation of smoking [90]. Longer periods of cessation of smoking appear to be more effective in reducing the incidence/risk of postoperative complications [91, 92]. There is translational high quality evidence for cessation of smoking at least 4 weeks preoperatively.

\section{Prehabilitation}

Prehabilitation can be defined as "the process of enhancing the functional capability of an individual in preparation for the surgical intervention". This process consists of: functional preoperative prehabilitation, nutritional and psychological intervention [93]. Pre-operative functional capacity is closely related to post-operative morbidity [66]. Whether improving the post-operative outcomes through prehabilitation has beneficial effects on mortality is not yet clear [94]. Multimodal prehabilitation in spinal surgery has been associated with improved recovery milestones, earlier discharge and appreciable improvement in patient satisfaction scores in the study group $[95,96]$. Health-economic benefits have been greater in patients having prehabilitation $[96,97]$. Patient reported outcomes such as readiness for surgery and perceived quality of life, were found to be improved by pre-operative neuroscience education and physiotherapy [98-100]. Overall evidence quality for prehabilitation is moderate.

\section{Preoperative nutritional care}

4.1. Nutritional assessment and screening Preoperative malnutrition as defined by hypoalbuminaemia, has been shown to be an independent risk factor for increased postoperative complication rates, including cardiorespiratory problems, and unplanned readmission within 30 days post discharge after elective spinal surgery [101-104]. Well-known risk factors for nutritional depletion in spinal surgery include: diagnosis of cerebral palsy, circumferential spinal surgery, fusion levels greater than or equal to 10, and age over 50 [88-105].

There is moderate quality evidence available for performance of risk assessment and screening of nutritional status in patients undergoing spinal surgery.

4.2. Perioperative immuno-nutrition Overall systematic evidence on immuno-nutrition (IN) in surgery has been contradictory [106, 107]. Clinical studies demonstrating benefit of IN are heterogenous with nonstandardized primary solutions, controls or timing of administration of supplements [108]. There is no evidence for use of IN in patients undergoing surgery of the spine.

\section{Management of anaemia}

Preoperative anemia is an independent risk factor for increased 30-day mortality and morbidity in surgical patients [109-112]. In patients undergoing surgery of the spine, preoperative anaemia was associated with increased length of stay $[113,114]$. Intraoperative blood transfusion in spinal surgery has been associated with increased postoperative complications, length of hospital stay and 30-day re-admission rates [115]. It is however unclear whether correcting iron deficiency anaemia improves reported outcomes, other than decreasing the risks associated with perioperative blood transfusion $[116,117]$. It is unknown whether correcting nonanaemic iron deficiency (NAID) decreases the risk of perioperative complications [118]. The association of iron replacement therapy, in particular intravenous format, with infection, is currently contentious $[119,120]$.

Clinically guided appropriate pre-operative use of intravenous or oral iron, vitamin B12, folic acid or erythropoietin for patients suffering from anaemia and/ or low iron stores should be implemented in patients undergoing moderate and major spinal surgery. There is moderate quality translational evidence for correcting the iron deficiency anaemia, in order to decrease the perioperative risk of complications secondary to blood transfusion.

\section{Perioperative blood conservation strategies}

Patients undergoing moderate and major spinal surgery are at risk of significant blood loss necessitating fluid and blood product replacement [121, 122]. Recent systematic analysis of tranexamic acid use in spinal surgery patients concluded that the use of tranexamic acid 
(TXA) was effective in reducing intra-operative blood loss and decreased the volume of blood transfusion [123]. It is likely that the higher bolus doses employed (greater or equal to $15 \mathrm{mg} / \mathrm{kg}$ followed by intraoperative infusion) were more effective in attenuating blood loss and transfusion requirements [124, 125]. Lower perioperative blood loss has consistently been demonstrated with the use of -amin-caproic acid (EACA) in spinal surgery [124]. Point of care testing devices allow for standardization of transfusion practices and early identification and treatment of hypofibrinogenemia [122]. In a study of patients undergoing major spinal surgery ROTEM (ROtational ThromboElastoMetry) device used with TXA was found to lead to a significantly lower blood loss and lower transfusion of packed red blood cells as compared to the TXA alone [126]. Studies have demonstrated the utility of ROTEM in decreasing the rate of blood product transfusion [127, 128].

Blood conservation options include preoperative autologous blood donation and intraoperative cell saver use.

Preoperative autologous blood donation in elective major spine surgery has been effective in reducing allogenic transfusion, however inclusion in the program resulted in increased risk of transfusion [129-131]. A Cochrane meta-analysis assessing the use of cell saver in major surgery demonstrated significantly decreased rate of allogenic blood transfusion [132]. The use of the cell saver in posterior spinal instrumentation and fusion surgery in school-aged children and adolescents was able to decrease the amount of intraoperative allogeneic RBC transfusion but failed to decrease total perioperative allogeneic RBC transfusion [133, 134]. In contrast, use of cell-saver was found to be associated with increased risk of bleeding in patients having spinal fusion surgery [135]. There is no evidence supporting the use of controlled hypotension to minimize the risk of bleeding, particularly in prone patients [136]. Perioperative blood conservation is aided through simple clinical measures such as temperature regulation, optimal patient positioning and meticulous surgical techniques.

There is high quality evidence for antifibrinolytic use in surgery of the spine when significant blood loss is anticipated. There is moderate quality evidence for cell saver use when significant blood loss is anticipated. There is low quality evidence for use of point of care testing to decrease the number of red blood cell units transfused.

\section{Pre-operative period}

\section{Preoperative fasting and carbohydrate loading}

In a randomized controlled trial examining patient population having co spinal surgery, preoperative carbohydrate loading did not attenuate postoperative insulin sensitivity [137]. This is contradictory to other general surgical trials which demonstrate improved insulin postoperative sensitivity with $\mathrm{CHO}$ loading [138-141]. The clinical relevance of administering preoperative $\mathrm{CHO}$ loading in patients with diabetes remains to be established [47]. Permitting patients to drink water or clear fluid preoperatively results in significantly lower gastric volumes [139]. International guidelines allow for unrestricted intake of clear fluids up to $2 \mathrm{~h}$ before elective surgery in patients not considered to have impaired gastric emptying [140, 142].

In spinal surgical patients without delayed gastric emptying standard societal fasting implementations can be made. Patients should be allowed to eat up until $6 \mathrm{~h}$ and take clear fluids including $\mathrm{CHO}$ drinks, up until $2 \mathrm{~h}$ before initiation of anaesthesia. Preoperative treatment with oral $\mathrm{CHOs}$ may not be suitable in patients with documented delayed gastric emptying, gastrointestinal motility disorders and in patients undergoing emergency surgery.

\section{Pre-emptive analgesia}

A number of studies found that pre-emptive administration of gabapentin reduced the opioid consumption and pain scores in the postoperative period in spinal patients [143-146]. The most effective dose in lowering the postoperative pain scores was found to be $600 \mathrm{mg}$ [144]. Impact of multimodal anti-inflammatory regimes combined with gabapentinoids, is significant in lowering the postoperative pain scores $[147,148]$. Parecoxib and ketorolac were found to be equally effective in improving postoperative pain measures. Both were superior to placebo in patients undergoing posterior lumbar fusion [149]. Preemptive epidural analgesia for thoracolumbar spine surgery has not been deemed effective [150].

Multimodal pre-emptive analgesia utilizing individual gabapentinoids and/or non-steroidal anti-inflammatory agents improves pain scores and functional measures in the immediate post-operative period. There is high quality evidence for preemptive administration of gabapentinoids in patients undergoing surgery of the spine.

There is moderate quality evidence for pre-emptive administration of multimodal anti-inflammatory regimes combined with gabapentinoids. Evidence quality is low for sole administration of individual anti-inflammatory agents.

\section{Intraoperative period}

\section{Prevention of nausea and vomiting (PONV)}

Postoperative nausea and vomiting (PONV) are amongst the most frequent postoperative complications, impacting the quality of recovery and causing patient dissatisfaction [151]. Patients should be risk-stratified according to the baseline risk of PONV. In patients undergoing 
spinal surgery a particular risk factor for increased PONV is the need for significant intraoperative and postoperative opioid administration. Standard societal guidelines for PONV prophylaxis and management apply to patients undergoing spinal surgery [151]. With nonpharmacological measures, avoidance of fasting and dehydration has been recommended. Multi-modal analgesia with opioid sparing effect has a beneficial influence on the risk of PONV $[152,153]$.

Risk assessment of patients according to the anaesthetic and procedural factors is recommended. Stepwise non-pharmacological and pharmacological PONV prophylaxis according to the guidelines is recommended. Use of anaesthetic techniques which minimize risk of PONV in high-risk patients should be considered.

There is high quality evidence for risk stratification of patients and appropriate anti-emetic prophylaxis.

There is moderate quality evidence for opioid sparing techniques as well as avoidance of nitrous oxide and volatile anaesthesia;

\section{Surgical site preparation and antimicrobial prophylaxis}

10.1. Surgical site preparation Reported post-operative infection rates in spinal surgery range from two to $13 \%$ [154].

Large prospective cohort studies have demonstrated that the surgical site infection rate is equivalent with both topical chlorhexidine gluconate and povidone in spinal surgical patients $[155,156]$. Topical chlorhexidine with alcohol compared to povidone alone, decreased the bacterial load significantly in spinal surgery $[157,158]$. A review evaluating randomized controlled trials in all types of surgeries concluded that alcohol-based agents are superior to aqueous solutions [159].

There is high quality evidence for using alcohol-based preparations. There is moderate quality evidence for decreasing the viable bacterial load utilizing CHG with alcohol solution.

10.2. Antimicrobial prophylaxis Risk factors for surgical site infections after spinal surgery include extended duration of procedure (longer than $2 \mathrm{~h}$ ), excessive blood loss (greater than one liter), staged procedure, multilevel fusion, foreign body placement, combined, anterior and posterior fusion, and poor peri-operative glycemic control [160]. Surgical site infection is less likely in procedures at the cervical spine level or with an anterior surgical approach [161]. Current guidelines recommend intravenous cephazolin as the first choice agent for antimicrobial prophylaxis for most surgical procedures [162]. In patients with MRSA, intravenous vancomycin is recommended $1 \mathrm{~h}$ prior to skin incision. Clindamycin is an acceptable alternative in patients with a cephalosporin or vancomycin allergy. In the setting of risk for
SSI due to gram-negative pathogens, an additional agent may be warranted (such as an aminoglycoside, aztreonam, or a fluoroquinolone). In order to ensure adequate antimicrobial serum and tissue concentrations, repeat intraoperative dosing is warranted for procedures that exceed two half-lives of the drug and for procedures in which there is excessive blood loss [162]. In a metaanalysis incorporating 6 prospective randomizedcontrolled trials, antibiotic prophylaxis was found to decrease the rate of infection [163]. Whether postoperative infections are reduced by continuing use of prophylactic antibiotics remains controversial [164]. In a metaanalysis consisting of 14 mostly class 3 evidence studies, vancomycin powder was found to decrease the likelihood of surgical site infection [165]. Vancomycin powder was found to decrease the rate of deep space infections requiring re-operation [166]. Vancomycin powder should be restricted to procedures and patients most at risk of MRSA-related surgical site infection [167-169].

Routine prophylaxis with cefazolin within $1 \mathrm{~h}$ prior to skin incision is recommended. Patients with MRSA should be treated prophylactically with vancomycin initiated $1 \mathrm{~h}$ prior to skin incision.

There is high quality evidence for intra-operative antibiotic prophylaxis. There is low quality evidence for use of intravenous vancomycin in patients at risk of MRSA.

\section{Local anaesthetic infiltration}

The benefits of intra-operative wound infiltration for postoperative analgesia in spinal surgery are controversial. A number of studies have demonstrated conflicting results in this area [170-173]. A meta-analysis of nine trials exploring the effect of wound infiltration in spinal surgery concluded that only a few trials observed a mild to modest pain score reduction. Of the trials which did show pain reduction, the analgesic benefit was noted in the immediate post-operative period [174].

Local anaesthetic wound infiltration in major spinal surgery has some immediate benefit on postoperative pain scores. There is moderate quality evidence for intra-operative administration of long-acting local anaesthetic administration.

\section{Standard Anaesthetic protocol}

Prior systematic reviews and meta-analysis have concluded that recovery parameters are improved with the use of total intravenous anaesthesia (TIVA) [175, 176]. There is some evidence that patients receiving TIVA had improved cognitive outcomes in post-anaesthesia recovery unit in all types of surgical patients [177]. Patients anesthetized with propofol-based TIVA reported less pain during coughing and consumed less daily and total PCA fentanyl after lumbar spine surgery [178]. This 
finding was not consistent across all studies [179]. Remifentanil, ultra-short acting phenyl-piperidine derivative is used in spinal surgery as part of total intravenous anaesthesia or inhalational anaesthesia protocols. Indications for use in spinal surgery include: improved endotracheal tube tolerance, improved surgical conditions and facilitations of peripheral neuromuscular monitoring. Severe postoperative pain after the intraoperative use of remifentanil has repeatedly been linked to the development of acute tolerance and/or opioid induced hyperalgesia [180]. In patients undergoing spinal fusion remifentanil dosage up to $0.16 \mathrm{mg} / \mathrm{kg} / \mathrm{min}$ did not cause an increased post-operative opioid consumption [181]. In contrast, in patients having correction of scoliosis where higher doses of remifentanil of $0.28 \mathrm{mcg} / \mathrm{kg} / \mathrm{min}$ were used for longer duration, the requirements for post-operative analgesia were $30 \%$ higher in the remifentanil group [182]. Neurologic monitoring in spinal surgery is performed using the intraoperative somatosensory potentials (SSEP's) and/or the Motor Evoked Potentials (MEP's). During the SSEP monitoring anaesthetic drugs produce a dose dependent increase in latency and a decrease in amplitude. The overall quality of SSEP is superior when propofol total intravenous anaesthesia is used. International Society of Intraoperative Neurophysiology recommends use of propofol and opioid [183]. MEP's display extreme sensitivity to the inhibitory effects of volatile agents even at concentrations as low as 0.25 MAC. Due to a lower level of interference with monitoring MEP's, propofol total intravenous anaesthesia is recommended for patients requiring spinal cord neurophysiological monitoring during surgery.

There is moderate quality evidence for use of total intravenous anaesthesia in patients undergoing surgery of the spine. There is low quality evidence for continuous intra-operative remifentanil infusion use in spine surgery.

\section{Surgical access (open and minimally invasive spinal surgery, including robotic surgery)}

Minimally Invasive Spinal Surgical (MISS) techniques can be viewed as a critical component of enhanced recovery in spinal surgery protocols (ERSS) [184]. Reduced length of stay together with significant cost saving has been identified in studies utilizing MISS techniques [32]. MISS techniques have been efficacious in decreasing postoperative pain in observational studies [185]. With a focus on minimally invasive transcutaneous lumbar inter-body fusion, Wang et al. demonstrated that ERAS in this group of patients was feasible and afforded improved early functional outcomes [186]. MISS approach studied within the enhanced recovery protocol was found to be effective in oncological spinal patients, where it was found to decrease the pain scores and lower the opioid consumption [187]. Significantly faster mobilization was demonstrated in patients undergoing minimally invasive thoracic inter-lumbar body fusion compared to open procedure [188]. In contrast to single studies and qualitative reviews, a quantitative metaanalysis found there was equipoise in patients undergoing lumbar minimally invasive procedures [189]. A multicenter study found equivalent outcomes for obese patients having spinal MISS or open techniques [190]. Conversely, Senkar et al. found minimally invasive surgical techniques had the highest utility in patients with multiple comorbidities [191].

There is evidence that minimally invasive surgical approaches improve pain scores, decrease opioid consumption and decrease length of stay, when used within the appropriate clinical context. There is moderate quality evidence for the intervention in appropriate clinical context.

\section{Maintenance of Normothermia}

Maintenance of normothermia has been shown to decrease the frequency of morbid cardiac events and the rate of blood product transfusion in major surgery [192, 193]. In spinal procedures with potential neurological cord compromise, maintenance of normothermia and avoidance of hyperthermia is recommended [194]. There is little scientific literature supporting the neuroprotective effects of hypothermia on the spinal cord in elective or emergency spinal surgery [195]. In pediatric spinal surgery maintenance of normothermia was found to be associated with a lower allogenic red blood cell transfusion rate [196]. In contrast hypothermia may be associated with a lower rate of acute kidney injury in spinal surgery under general anaesthesia [197].

Measures to maintain normothermia should be implemented in spinal surgical patients. There is moderate quality evidence for maintenance of intraoperative normothermia.

\section{Intraoperative fluid and electrolyte therapy}

For the minor range of spinal surgeries intraoperative fluid management goals are achievable with routine monitoring. In major surgery, goal-directed therapy has been recommended [198]. Advanced haemodynamic monitoring equipment chosen should be based on a clinical risk-management strategy and patient, anaesthetic, surgical and institutional factors. Prior meta-analysis have demonstrated that pre-emptive hemodynamic monitoring and proactive therapy reduces mortality and morbidity in major surgical procedures $[199,200]$. In a retrospective observational trial in patients undergoing prone spinal surgery, goal directed fluid management was found to decrease blood loss and transfusion, improve postoperative respiratory 
performance and allow for faster return of bowel function [201]. In contrast, liberal fluid strategy was associated with an increased rate of pulmonary complications [202].

Goal-directed fluid management may decrease the rate of complications and duration of stay when implemented in the appropriate clinical context. There is low quality evidence for goal-directed intraoperative fluid management using contextually appropriate indicators and measurements of cardiac output in patients undergoing major surgery of the spine.

\section{Peri-operative analgesia}

Poorly controlled pain in the post-operative period can influence mobility and result in increased rate of complications of deep venous thrombosis, pulmonary embolism and pneumonia [203].

NSAIDS and acetaminophen A recent meta-analysis of eight trials identified that NSAIDs are effective in postoperative analgesia after lumbar spine surgery. The study found that NSAID dose, different surgery types, and analgesic type might influence the efficacy of NSAIDs [204]. A meta-analysis of 17 studies demonstrated that addition of NSAIDs to opioid analgesics alone resulted in lower pain scores and less morphine equivalents consumed [205]. In a meta-analysis of seven spine fusion studies, no statistically significant association between NSAID exposure and nonunion was identified (odds ratio $=2.2$, 95\% confidence interval 0.8-6.3) [206]. It is likely that adverse effects of NSAID's on bone healing/ fusion in adult spine surgery are dose-dependent [207]. While there is limited evidence for the use of acetaminophen specifically in spinal surgery, it is a well-established analgesic agent for a wide range of related surgeries [203].

N-methyl D-aspartate antagonists Randomized controlled trials demonstrating decreased opioid consumption and lower pain scores following intraoperative and post-operative ketamine [208-210]. These findings are in line with a meta-analysis of eight trials [211]. A single study showed no benefit of low dose ketamine in major lumbar surgery [212]. Methadone and magnesium through their NMDA antagonism may also be of benefit; however, data are limited and further studies are indicated [213-215].

Alpha-2 receptor agonists Data supporting the use of alpha-2 receptor agonists in major spine surgery are limited; studies have demonstrated conflicting findings [216].
Gabapentinoids In a systematic review and metaanalysis by $\mathrm{Yu}$ et al., perioperative administration of gabapentinoids was found to decrease opioid consumption and pain intensity in the immediate post-operative period [145]. Other high quality prospective studies have deemed gabapentinoids effective at reducing the opioid consumption when continued for at least $24 \mathrm{~h}$ postoperatively [146]. A prospective, double-blind study, randomized control trial by Khurana et al. showed a stronger benefit for pregabalin over gabapentin versus placebo for pain and functional status in the postoperative period and at 3 months [217].

Intravenous lignocaine In a number of controlled trials in both adult and pediatric major and minor spine surgery, perioperative lignocaine infusion was demonstrated to improve pain scores and decrease opioid consumption [218-221]. Conversely, in a randomized controlled trial of 70 patients undergoing posterior spine surgery, there was no analgesic benefit of a systemic lignocaine infusion as compared to placebo [222].

Regional analgesia Intrathecal morphine administration in a wide dosage range as a single injection has been found to be effective as a postoperative analgesic in spinal surgery, though doses greater than six mcg, $\mathrm{kg}^{-1}$ are associated with postoperative respiratory depression [223-230]. In a meta-analysis of eight randomized controlled trials, intrathecal morphine was an effective analgesic [231].

Multimodal regimens Prior review articles have highlighted multimodal analgesia as a significant contributor to enhanced recovery in spinal surgery [10, 203, 232]. Multimodal analgesia bundles have been incorporated into most care pathways of enhanced recovery in spinal surgery [8, 12, 233]. A numbed of retrospective studies have demonstrated decreased pain measurement outcomes including post-operative opioid consumption [234-237]. In contrast to other studies, a single randomized controlled trial of optimally dosed multimodal regime did not show any benefit over the placebo components when evaluated in terms of quality of recovery scores or analgesic components [238]. Minimally invasive opioid free enhanced recovery protocols in spinal surgery have been shown to have a favorable profile on perioperative opioid consumption [239].

Simple analgesics such as acetaminophen and NSAIDs are safe and efficacious, particularly in combination. There is high quality evidence for perioperative administration of NSAID's. Ketamine in both intraoperative and post-operative infusions, reduces pain scores, opioid requirements in the immediate and late post-operative phases. There is moderate quality for intraoperative 
ketamine administration. There is very low quality evidence for administration of other NMDA antagonists and alpha-2-agonists. There is high quality evidence for perioperative gabapentinoid administration. Consideration should be given to perioperative intravenous lignocaine infusion administration. There is moderate quality evidence for perioperative intravenous lignocaine administration. There is moderate quality evidence for use of intrathecal morphine in spinal surgery, although its utility may be limited by logistical factors. Clinically appropriate multimodal opioid-sparing regimens should be considered in all patients undergoing spine surgery. There is moderate quality evidence for instituting perioperative multimodal analgesia.

\section{Postoperative period}

\section{Thromboprophylaxis}

Mechanical thromboprophylaxis is a proven measure to decrease the risk of deep venous thrombosis (DVT) in the absence of chemoprophylaxis [240]. A meta-analysis conducted in 2018 found that the incidence of DVT and pulmonary embolism (PE) in spinal surgical population was relatively low regardless of prophylaxis type. The authors commented that there was a higher mean incidence of DVT and PE in the mechanoprophylaxis group (DVT: $1 \%$, PE: $0.81 \%$ ) compared to the chemoprophylaxis group (DVT: 0.85\%, PE: 0.58\%) [241]. In this study, when PE occurred it was fatal in $6 \%$ of patients. Perception of true incidence of post-operative epidural haematoma in spinal surgical patients is varied [242].

Patients undergoing spinal surgery should have mechanical thromboprophylaxis by well-fitting compression stockings and/or intermittent pneumatic compression until discharge. There is moderate quality evidence for postoperative mechanical thromboprophylaxis in patients undergoing spinal surgery.

There is low quality evidence for postoperative chemical thromboprophylaxis in patients undergoing spinal surgery.

\section{Urinary drainage}

Urinary catheter use beyond $48 \mathrm{~h}$ following surgery has been associated with an increase in hospital-acquired urinary tract infections and 30-day mortality [243]. In a nested cohort study in a neurological intensive care unit, an increased rate of urinary infection was noted in patients, where catheter remained in place for longer than 7 days [244]. Risk factors for postoperative urinary retention in spinal surgery include older age, benign prostatic hypertrophy, chronic constipation, longer duration of surgery and posterior spinal fusion [245-247].

If urinary drainage is indicated, the duration of catheterization should be individualized based on known risk factors for urinary retention. There is moderate quality evidence for urinary catheter removal within $48 \mathrm{~h}$ after surgery.

\section{Postoperative nutrition and fluid management}

Many of the studies report on early mobilization in conjunction with dietary libertization [185, 248]. When performed together, the two can reduce length of stay and costs without increasing early or late complications in adolescents undergoing posterior spinal fusion [249]. Results of the RELIEF trial suggest that we should be more cautious with postoperative restrictive fluid strategies in patients having major abdominal surgery [250]. In patients having major spine surgery, goal orientated postoperative fluid management may be more appropriate than a restrictive approach, although specific evidence is currently lacking. Intraoperative haemodynamic framework may be continued into the post-operative period in the high-risk patient group. In line with other ERAS guidelines patients should be encouraged to transition as early as tolerated to oral intake.

\section{Postoperative glycemic control}

A retrospective cohort study incorporating population undergoing spine surgery found that perioperative hyperglycemia increases the risk of adverse postoperative events in the non-diabetic patient group [251]. Tighter glycemic control may mitigate the risk of surgical site infection in patients with diabetes [252]. There remains insufficient evidence that strict glycemic control is advantageous over conventional management for prevention of surgical site infection [253]. Although it is clear that perioperative hyperglycemia is deleterious, the optimal management paradigm in the postoperative period remains uncertain [252].

It is prudent to maintain more conventional blood glucose target in the postoperative period in patients undergoing spinal surgery. There is low quality evidence for conventional postoperative blood glucose control.

\section{Early mobilization}

Early mobilization is thought to be a key component of ERSS [12, 254]. There is no clear definition of mobilizing, which may include simple exercise in bed, walking in the room or walking further distances [47]. The overall outcome of these pathways has been that of significant decreased length of stay; as well as improved patient satisfaction measures in selected studies [185, 233, 248, 255-257]. A study focusing on behavioral outcomes of early mobilization and rehabilitation education, identified decreased postoperative patient anxiety and enhanced self-care ability [258]. Reduced complication rates, improved patient-reported outcomes and decreased length of stay were noted in a narrative review in patients undergoing early mobilization [259]. 
Patients should be encouraged to mobilize actively on the day of surgery as guided by clinical condition and surgical concerns. In the absence of a clear definition of early mobilization, institutions should be encouraged to set their own benchmarks. There is moderate quality evidence for the intervention due to the imprecision in defining mobilization as well as retrospective nature of studies.

\section{Quality of care measures}

\section{Audit}

Systematic audit is the preferred practice pattern in order to review compliance rates with the ERAS implemented interventions [260]. There is evidence in retrospective studies that greater compliance with ERAS processes and protocols improves desired perioperative outcomes [261-264]. Full compliance with ERAS protocols has been identified to be an issue in prior studies. Compliance with ERAS pathways has been deemed to be a 5-year survival measure [265]. Overall compliance with ERAS protocols has been shown to be associated with better patient reported outcome measures [266]. There is a paucity of audit data in multimodal ERSS protocols.

\section{Implications of this study and future directions}

We have identified, delineated and presented the evidence base for first comprehensive multimodal program for Enhanced Recovery in Spinal Surgery (ERSS). A continuous issue when discussing enhanced recovery protocols is that of contention as to which components have the highest clinical utility, accompanied by somewhat arbitrary decisions on incorporating different elements into the program. We identified a high level of evidence for administration of pre-emptive analgesia, peri-operative blood conservation (antifibrinolytic use), surgical site preparation and antibiotic prophylaxis. Although evidence base for cessation of smoking in surgery of the spine is low, there is translational high level evidence from other surgical specialties. In contrast with prior ERSS reviews we identified moderate evidence base for utilization of minimally invasive surgery and use of multimodal analgesia [12]. Although early mobilization and dietary libertization are considered critical in enhanced recovery, we identified a moderate level of evidence for institution of these interventions. Some clinical units may choose to use certain aspects of this proposed perioperative program as suited best to their unique location and practice pattern.

Evidence base is low in certain research areas. Most of the studies assessed were conducted outside the context of enhanced recovery program. This may have a negative bias effect, where the effect of an individual component may be higher than estimated when used within the ERSS pathway. Their combination with other components in a particular pathway is thought to have a synergistic effect. In addition to including studies focusing on individual ERSS elements, we evaluated studies focusing on bundles of care. Through the additive incremental value of each component, this may have a positive bias towards patient care outcomes. Full compliance with ERAS protocols has been identified to be an issue in prior studies. Compliance with ERAS pathways has been deemed to be a 5-year survival measure [265]. Overall compliance with ERAS protocols has been shown to be associated with better patient reported outcome measures [266].

Methodologically heterogenous studies including systematic reviews and meta-analysis, randomized controlled trials, non-randomized controlled studies, and observational studies were eligible for this review. Hence, methodological heterogeneity of included studies rendered any quantitative effect estimates unreliable. In line with our planned protocol, we did not conduct a metaanalysis of studies in this patient population. Inherent clinical heterogeneity was present in this complex systematic review of a multi-pathway intervention. Clinical heterogeneity arose from variability in the participants, types and timing of outcome measures. Participants varied in their nature due to the type of baseline disease (e.g. ERSS for surgery on anatomically abnormal spine versus ERSS in cancer patient population). Participants also varied in inherent comorbidities e.g. young patients undergoing scoliosis surgery versus elderly with comorbidities. These multilevel participant heterogenous characteristics were combined with varied baseline analgesic consumption. Types and timing of outcome measures were compliant with our pre-determined outcome groups. As anticipated, outcome measures were broadly different to be suitable for meta-analytic process. Forest plots were obtained for some pre-determined outcomes however the statistical heterogeneity together with baseline clinical differences made these measures inappropriate for interpretation. In line with our protocol, we performed a pre-planned thematic synthesis.

We have undertaken a number of steps to minimize the underlying meta-biases in this systematic review of complex intervention. We disseminated this protocol through open literature in order to give transparency to our research structure. We assessed the risk of bias in all individual studies. Furthermore, we graded the risk of bias across outcomes [267]. As we have identified 22 components of this pathway, some selection bias due to not identifying all eligible studies was possible. Publication bias across studies, where only data published through positive findings are disseminated poses a risk in any systematic review. Detection bias may have arisen due to problems with classification of exposure or outcomes.

\section{Conclusion}

This pathway with an evaluated evidence underpinning each component integrates existing knowledge into 
practice. Comprehensive evidence based program facilitates institutional perioperative care of spinal surgical patients in the field of ERSS.

\section{Abbreviations}

ERSS: Enhanced Recovery after Spinal Surgery; ERAS: Enhanced Recovery after Surgery; PREMs/PROMs: Patient-reported experiences and outcomes; GRADE: Grading of Recommendations, Assessment, Development and Evaluation; EP: Evidence Profile; MRSA: Methicillin Resistant Staph Aureus; DVT: Deep venous thrombosis; PE: Pulmonary embolism

\section{Supplementary Information}

The online version contains supplementary material available at https://doi. org/10.1186/s12871-021-01281-1.

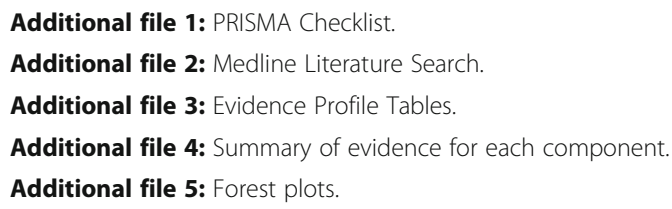

\section{Acknowledgements}

The authors gratefully acknowledge Mr. S. Heaton for his help in data collection.

\section{Authors' contributions}

AL: study development, data collection, data editing; first draft manuscript: final version of manuscript; AS: study development, data collection, manuscript editing, final version of manuscript; HL study design, manuscript editing; JR: study design, manuscript editing; CW: study design, manuscript editing; All authors approved the final manuscript

\section{Funding}

No external funding

\section{Availability of data and materials}

The datasets used and/or analyzed during the current study are available from the corresponding author on reasonable request

\section{Declarations}

\section{Ethics approval and consent to participate}

Not applicable as this was a systematic review of available literature;

\section{Consent for publication}

Not applicable as this was a systematic review of available literature;

\section{Competing interests}

The authors declare that they have no competing interests.

\section{Author details \\ ${ }^{1}$ Austin Health, 145 Studley Road, Heidelberg, Victoria 3084, Australia. ${ }^{2}$ Monash Health, Clayton, Australia, Faculty of Medicine, Nursing and Health Science, Monash University, Melbourne, Victoria, Australia. ${ }^{3}$ Royal Hobart Hospital, Hobart, Tasmania, Australia. ${ }^{4}$ Department of Neurosurgery, Austin Health, Melbourne, Victoria, Australia. ${ }^{5}$ St Vincent's Hospital, Melbourne, Australia.}

Received: 16 June 2020 Accepted: 16 February 2021 Published online: 10 March 2021

\section{References}

1. Gustafsson UO, Scott MJ, Hubner M, Nygren J, Demartines N, Francis N, et al. Guidelines for perioperative Care in Elective Colorectal Surgery: enhanced recovery after surgery (ERAS((R))) society recommendations: 2018. World J Surg. 2019;43(3):659-95.
2. Nicholson A, Lowe MC, Parker J, Lewis SR, Alderson P, Smith AF. Systematic review and meta-analysis of enhanced recovery programmes in surgical patients. Br J Surg. 2014;101(3):172-88.

3. Raciborski F, Gasik R, Klak A. Disorders of the spine. A major health and social problem. Reumatologia. 2016;54(4):196-200.

4. Martin BI, Mirza SK, Spina N, Spiker WR, Lawrence B, Brodke DS. Trends in lumbar fusion procedure rates and associated hospital costs for degenerative spinal diseases in the United States, 2004 to 2015. Spine. 2019;44(5):369-76.

5. Venkata HK, van Dellen JR. A perspective on the use of an enhanced recovery program in open, non-instrumented day surgery for degenerative lumbar and cervical spinal conditions. J Neurosurg Sci. 2018;62(3):245-54.

6. Sanders AE, Andras LM, Sousa T, Kissinger C, Cucchiaro G, Skaggs DL. Accelerated discharge protocol for posterior spinal fusion patients with adolescent idiopathic scoliosis decreases hospital postoperative charges 22. Spine (Phila Pa 1976). 2017:42(2):92-7.

7. Brusko GD, Kolcun JPG, Heger JA, Levi AD, Manzano GR, Madhavan K, et al. Reductions in length of stay, narcotics use, and pain following implementation of an enhanced recovery after surgery program for 1- to 3level lumbar fusion surgery. Neurosurg Focus. 2019:46(4):E4.

8. Staartjes VE, de Wispelaere MP, Schroder ML. Improving recovery after elective degenerative spine surgery: 5-year experience with an enhanced recovery after surgery (ERAS) protocol. Neurosurg Focus. 2019;46(4):E7.

9. Staartjes VE, de Wispelaere MP, Vandertop WP, Schroder ML. Deep learningbased preoperative predictive analytics for patient-reported outcomes following lumbar diskectomy: feasibility of center-specific modeling. Spine J. 2018;19(5):853-61.

10. Wainwright TW, Immins T, Middleton RG. Enhanced recovery after surgery (ERAS) and its applicability for major spine surgery. Best Pract Res Clin Anaesthesiol. 2016;30(1):91-102.

11. Licina A, Silvers A, Laughlin H, Russell J, Wan C. Proposed pathway for patients undergoing enhanced recovery after spinal surgery: protocol for a systematic review. Syst Rev. 2020:9(1):39.

12. Elsarrag M, Soldozy S, Patel P, Norat P, Sokolowski JD, Park MS, et al. Enhanced recovery after spine surgery: a systematic review. Neurosurg Focus. 2019:46(4):E3.

13. Batchelor TJP, Rasburn NJ, Abdelnour-Berchtold E, Brunelli A Cerfolio RJ Gonzalez M, et al. Guidelines for enhanced recovery after lung surgery: recommendations of the enhanced recovery after surgery (ERAS(R)) society and the European Society of Thoracic Surgeons (ESTS). Eur J Cardiothorac Surg. 2019;55(1):91-115.

14. Nelson G, Altman AD, Nick A, Meyer LA, Ramirez PT, Achtari C, et al. Guidelines for postoperative care in gynecologic/oncology surgery: enhanced recovery after surgery (ERAS(R)) society recommendations--part II. Gynecol Oncol. 2016;140(2):323-32.

15. Deng QF, Gu HY, Peng WY, Zhang Q, Huang ZD, Zhang C, et al. Impact of enhanced recovery after surgery on postoperative recovery after joint arthroplasty: results from a systematic review and meta-analysis. Postgrad Med J. 2018;94(1118):678-93.

16. Zhu S, Qian W, Jiang C, Ye C, Chen X. Enhanced recovery after surgery for hip and knee arthroplasty: a systematic review and meta-analysis. Postgrad Med J. 2017:93(1106):736-42.

17. Azhar RA, Bochner B, Catto J, Goh AC, Kelly J, Patel HD, et al. Enhanced recovery after urological surgery: a contemporary systematic review of outcomes, key elements, and research needs. Eur Urol. 2016;70(1):176-87.

18. Cerantola Y, Valerio M, Persson B, Jichlinski P, Ljungqvist O, Hubner M, et al. Guidelines for perioperative care after radical cystectomy for bladder cancer: Enhanced Recovery After Surgery (ERAS((R))) society recommendations. Clin Nutr (Edinburgh, Scotland). 2013;32(6):879-87.

19. Ljungqvist $\mathrm{O}$, Scott $M$, Fearon $\mathrm{KC}$. Enhanced recovery after surgery: a review. JAMA Surg. 2017;152(3):292-8.

20. Melloul E, Hubner M, Scott M, Snowden C, Prentis J, Dejong CH, et al. Guidelines for perioperative Care for Liver Surgery: enhanced recovery after surgery (ERAS) society recommendations. World J Surg. 2016;40(10):2425-40

21. Guyatt GH, Oxman AD, Kunz R, Falck-Ytter Y, Vist GE, Liberati A, et al. Going from evidence to recommendations. BMJ. 2008;336(7652):1049-51.

22. Guise JM, Butler M, Chang C, Viswanathan M, Pigott T, Tugwell P. AHRQ series on complex intervention systematic reviews-paper 7: PRISMA-CI elaboration and explanation. J Clin Epidemiol. 2017:90:51-8.

23. Guise JM, Butler ME, Chang C, Viswanathan M, Pigott T, Tugwell P. AHRQ series on complex intervention systematic reviews-paper 6: PRISMA-C extension statement and checklist. J Clin Epidemiol. 2017;90:43-50. 
24. Guise JM, Chang C, Butler M, Viswanathan M, Tugwell P. AHRQ series on complex intervention systematic reviews-paper 1: an introduction to a series of articles that provide guidance and tools for reviews of complex interventions. J Clin Epidemiol. 2017;90:6-10.

25. Higgins JPT, López-López JA, Becker BJ, Davies SR, Dawson S, Grimshaw JM, et al. Synthesising quantitative evidence in systematic reviews of complex health interventions. BMJ Glob Health. 2019;4(Suppl 1):e000858.

26. Kelly MP, Noyes J, Kane RL, Chang C, Uhl S, Robinson KA, et al. AHRQ series on complex intervention systematic reviews-paper 2: defining complexity, formulating scope, and questions. J Clin Epidemiol. 2017;90:11-8.

27. Pigott T, Noyes J, Umscheid CA, Myers E, Morton SC, Fu R, et al. AHRQ series on complex intervention systematic reviews-paper 5: advanced analytic methods. J Clin Epidemiol. 2017;90:37-42.

28. Viswanathan M, McPheeters ML, Murad MH, Butler ME, Devine EEB, Dyson $M P$, et al. AHRQ series on complex intervention systematic reviews-paper 4: selecting analytic approaches. J Clin Epidemiol. 2017;90:28-36.

29. Cochrane Handbook for Systematic Reviews of Interventions Version 5.1.0 [updated Mach 2011]. JPT Higgins SG, editor: The Cochrane Collaboration; 2011.

30. Swartz MK. The PRISMA statement: a guideline for systematic reviews and meta-analyses. J Pediatr Health Care. 2011;25:1-2.

31. CRD42019135289. Proposed pathway for patients undergoing enhanced recovery after spinal surgery-protocol for a systematic narrative review of evidence 2019 [Available from: https://www.crd.york.ac.uk/prospero.

32. Corniola MV, Debono B, Joswig H, Lemée J-M, Tessitore E. Enhanced recovery after spine surgery: review of the literature. J Neurosurg. 2019;46(4): E2.

33. Balshem $H$, Helfand $M$, Schunemann HJ, Oxman AD, Kunz R, Brozek J, et al GRADE guidelines: 3. Rating the quality of evidence. J Clin Epidemiol. 2011; 64(4):401-6.

34. Gotlib Conn L, Rotstein OD, Greco E, Tricco AC, Perrier L, Soobiah C, et al. Enhanced recovery after vascular surgery: protocol for a systematic review. Syst Rev. 2012;1:52.

35. Butler M, Epstein RA, Totten A, Whitlock EP, Ansari MT, Damschroder LJ et al. AHRQ series on complex intervention systematic reviews-paper 3: adapting frameworks to develop protocols. J Clin Epidemiol. 2017:90:19-27.

36. Haddaway NR, Collins AM, Coughlin D, Kirk S. The role of Google scholar in evidence reviews and its applicability to Grey literature searching. PLoS One. 2015;10(9):e0138237.

37. Mahood Q, Van Eerd D, Irvin E. Searching for grey literature for systematic reviews: challenges and benefits. Res Synth Methods. 2014;5(3):221-34.

38. Paez A. Grey literature: an important resource in systematic reviews. J Evid Based Med. 2017;10(3):233-40.

39. Verhagen AP, de Vet HC, de Bie RA, Kessels AG, Boers M, Bouter LM, et al. The Delphi list: a criteria list for quality assessment of randomized clinical trials for conducting systematic reviews developed by Delphi consensus. J Clin Epidemiol. 1998;51(12):1235-41.

40. Sterne JAC, Savovic J, Page MJ, Elbers RG, Blencowe NS, Boutron I, et al. RoB 2: a revised tool for assessing risk of bias in randomised trials. BMJ(Clin Res). 2019;366:14898.

41. Sterne JA, Hernán MA, Reeves BC, Savović J, Berkman ND, Viswanathan M, et al. ROBINS-I: a tool for assessing risk of bias in non-randomised studies of interventions. BMJ (Clin Res ed). 2016;355:i4919.

42. Shea BJ, Reeves BC, Wells G, Thuku M, Hamel C, Moran J, et al. AMSTAR 2: a critical appraisal tool for systematic reviews that include randomised or non-randomised studies of healthcare interventions, or both. BMJ. 2017;358: j4008.

43. Guyatt G, Oxman AD, Akl EA, Kunz R, Vist G, Brozek J, et al. GRADE guidelines: 1. Introduction-GRADE evidence profiles and summary of findings tables. J Clin Epidemiol. 2011;64(4):383-94.

44. Licina A, Silvers A, Stuart RL. Use of powered air-purifying respirator (PAPR) by healthcare workers for preventing highly infectious viral diseases-a systematic review of evidence. Syst Rev. 2020;9(1):173.

45. Brozek JL, Akl EA, Compalati E, Kreis J, Terracciano L, Fiocchi A, et al. Grading quality of evidence and strength of recommendations in clinical practice guidelines part 3 of 3 . The GRADE approach to developing recommendations. Allergy. 2011;66(5):588-95.

46. Abola RE, Bennett-Guerrero E, Kent ML, Feldman LS, Fiore JF Jr, Shaw AD, et al. American Society for Enhanced Recovery and Perioperative Quality Initiative Joint Consensus Statement on patient-reported outcomes in an enhanced recovery pathway. Anesth Analg. 2018;126(6):1874-82.
47. Feldheiser A, Aziz O, Baldini G, Cox BPBW, Fearon KCH, Feldman LS, et al. Enhanced recovery after surgery (ERAS) for gastrointestinal surgery, part 2 consensus statement for anaesthesia practice. Acta Anaesthesiol Scand. 2016;60(3):289-334.

48. Atkins $D$, Best D, Briss PA, Eccles M, Falck-Ytter Y, Flottorp S, et al. Grading quality of evidence and strength of recommendations. BMJ. 2004;328(7454):1490.

49. Gustafsson UO, Scott MJ, Schwenk W, Demartines N, Roulin D, Francis N, et al. Guidelines for perioperative care in elective colonic surgery: enhanced recovery after surgery (ERAS(R)) society recommendations. Clin Nutr. 2012; 31(6):783-800.

50. Grocott MP, Martin DS, Mythen MG. Enhanced recovery pathways as a way to reduce surgical morbidity. Curr Opin Crit Care. 2012;18(4):385-92.

51. Blitz JD, Kendale SM, Jain SK, Cuff GE, Kim JT, Rosenberg AD. Preoperative evaluation clinic visit is associated with decreased risk of in-hospital postoperative mortality. Anesthesiology. 2016;125(2):280-94.

52. Granziera E, Guglieri I, Del Bianco P, Capovilla E, Dona B, Ciccarese AA, et al. A multidisciplinary approach to improve preoperative understanding and reduce anxiety: a randomised study. Eur J Anaesthesiol. 2013;30(12):734-42.

53. Sjoling M, Nordahl G, Olofsson N, Asplund K. The impact of preoperative information on state anxiety, postoperative pain and satisfaction with pain management. Patient Educ Couns. 2003;51(2):169-76.

54. Wongkietkachorn A, Wongkietkachorn N, Rhunsiri P. Preoperative needsbased education to reduce anxiety, increase satisfaction, and decrease time spent in day surgery: a randomized controlled trial. World J Surg. 2018;42(3): 666-74.

55. Powell R, Scott NW, Manyande A, Bruce J, Vogele C, Byrne-Davis LM, et al. Psychological preparation and postoperative outcomes for adults undergoing surgery under general anaesthesia. Cochrane Database Syst Rev. 2016;5:CD008646.

56. Marek RJ, Block AR, Ben-Porath YS. The Minnesota multiphasic personality Inventory-2-restructured form (MMPI-2-RF): incremental validity in predicting early postoperative outcomes in spine surgery candidates. Psychol Assess. 2015;27(1):114-24

57. Trief PM, Ploutz-Snyder R, Fredrickson BE. Emotional health predicts pain and function after fusion: a prospective multicenter study. Spine (Phila Pa 1976). 2006:31(7):823-30.

58. Derby R, Lettice JJ, Kula TA, Lee SH, Seo KS, Kim BJ. Single-level lumbar fusion in chronic discogenic low-back pain: psychological and emotional status as a predictor of outcome measured using the 36-item short form. J Neurosurg Spine. 2005;3(4):255-61.

59. Grocott MPW, Edwards M, Mythen MG, Aronson S. Peri-operative care pathways: re-engineering care to achieve the 'triple aim'. Anaesthesia. 2019; 74(Suppl 1):90-9.

60. Pearse RM, Harrison DA, James P, Watson D, Hinds C, Rhodes A, et al. Identification and characterisation of the high-risk surgical population in the United Kingdom. Crit Care. 2006;10(3):R81.

61. Bisbe E, Garcia-Erce JA, Diez-Lobo Al, Munoz M, Anaemia Working Group Espana. A multicentre comparative study on the efficacy of intravenous ferric carboxymaltose and iron sucrose for correcting preoperative anaemia in patients undergoing major elective surgery. Br J Anaesth. 2015;107(3): 477-8. https://doi.org/10.1093/bja/aer242. Br J Anaesth. 2015;115(1):154.

62. Fleisher LA, Fleischmann KE, Auerbach AD, Barnason SA, Beckman JA, Bozkurt B, et al. 2014 ACC/AHA guideline on perioperative cardiovascular evaluation and Management of Patients Undergoing Noncardiac Surgery. Circulation. 2014;130(24):e278-333.

63. Lee TH, Marcantonio ER, Mangione CM, Thomas EJ, Polanczyk CA, Cook $E F$, et al. Derivation and prospective validation of a simple index for prediction of cardiac risk of major noncardiac surgery. Circulation. 1999; 100(10):1043-9.

64. Sankar A, Beattie WS, Wijeysundera DN. How can we identify the high-risk patient? Curr Opin Crit Care. 2015;21(4):328-35.

65. Prytherch DR, Whiteley MS, Higgins B, Weaver PC, Prout WG, Powell SJ. POSSUM and Portsmouth POSSUM for predicting mortality. Physiological and operative severity score for the enUmeration of mortality and morbidity. Br J Surg. 1998;85(9):1217-20.

66. Wijeysundera DN, Pearse RM, Shulman MA, Abbott TEF, Torres E, Ambosta A, et al. Assessment of functional capacity before major noncardiac surgery: an international, prospective cohort study. Lancet. 2018; 391(10140):2631-40

67. Bilimoria KY, Liu Y, Paruch JL, Zhou L, Kmiecik TE, Ko CY, et al. Development and evaluation of the universal ACS NSQIP surgical risk calculator: a decision 
aid and informed consent tool for patients and surgeons. J Am Coll Surg. 2013;217(5):833-842.e1-3.

68. Cohen ME, Liu Y, Ko CY, Hall BL. An examination of American College of Surgeons NSQIP surgical risk calculator accuracy. J Am Coll Surg 2017;224(5): 787-795 e1.

69. Basques BA, Fu MC, Buerba RA, Bohl DD, Golinvaux NS, Grauer JN. Using the ACS-NSQIP to identify factors affecting hospital length of stay after elective posterior lumbar fusion. Spine (Phila Pa 1976). 2014;39(6):497-502.

70. Passias PG, Poorman GW, Delsole E, Zhou PL, Horn SR, Jalai CM, et al. Adverse outcomes and prediction of cardiopulmonary complications in elective spine surgery. Global Spine J. 2018;8(3):218-23.

71. Devereaux PJ, Goldman L, Cook DJ, Gilbert K, Leslie K, Guyatt GH. Perioperative cardiac events in patients undergoing noncardiac surgery: a review of the magnitude of the problem, the pathophysiology of the events and methods to estimate and communicate risk. CMAJ. 2005;173(6): 627-34.

72. Copeland GP, Jones D, Walters M. POSSUM: a scoring system for surgical audit. Br J Surg. 1991;78(3):355-60.

73. Griffiths R, Beech F, Brown A, Dhesi J, Foo I, Goodall J, et al. Peri-operative care of the elderly 2014: Association of Anaesthetists of Great Britain and Ireland. Anaesthesia. 2014;69(Suppl 1):81-98.

74. Chow WB, Rosenthal RA, Merkow RP, Ko CY, Esnaola NF. Optimal preoperative assessment of the geriatric surgical patient: a best practices guideline from the American College of Surgeons National Surgical Quality Improvement Program and the American Geriatrics Society. J Am Coll Surg. 2012;215(4):453-66.

75. Qaseem A, Snow V, Fitterman N, Hornbake ER, Lawrence VA, Smetana GW, et al. Risk assessment for and strategies to reduce perioperative pulmonary complications for patients undergoing noncardiothoracic surgery: a guideline from the American College of Physicians. Ann Intern Med. 2006; 144(8):575-80

76. McGuire KJ, Khaleel MA, Rihn JA, Lurie JD, Zhao W, Weinstein JN. The effect of high obesity on outcomes of treatment for lumbar spinal conditions: subgroup analysis of the spine patient outcomes research trial. Spine (Phila Pa 1976). 2014;39(23):1975-80.

77. Onyekwelu I, Glassman SD, Asher AL, Shaffrey Cl, Mummaneni PV, Carreon LY. Impact of obesity on complications and outcomes: a comparison of fusion and nonfusion lumbar spine surgery. J Neurosurg Spine. 2017;26(2): 158-62.

78. Armaghani SJ, Archer KR, Rolfe R, Demaio DN, Devin CJ. Diabetes is related to worse patient-reported outcomes at two years following spine surgery. J Bone Joint Surg Am. 2016;98(1):15-22.

79. Moazzeni K, Kazemi KA, Khanmohammad R, Eslamian M, Rostami M, Faghih-Jouibari M. Comparison of surgical outcome between diabetic versus nondiabetic patients after lumbar fusion. Int I Spine Surg. 2018; 12(4):528-32.

80. Luo W, Sun RX, Jiang $H, M a X L$. The effect of diabetes on perioperative complications following spinal surgery: a meta-analysis. Ther Clin Risk Manag. 2018;14:2415-23.

81. Chan SP, Ip KY, Irwin MG. Peri-operative optimisation of elderly and frail patients: a narrative review. Anaesthesia. 2019;74(S1):80-9.

82. Tonnesen $\mathrm{H}$, Kehlet $\mathrm{H}$. Preoperative alcoholism and postoperative morbidity. Br J Surg. 1999;86(7):869-74.

83. Eliasen M, Gronkjaer M, Skov-Ettrup LS, Mikkelsen SS, Becker U, Tolstrup JS, et al. Preoperative alcohol consumption and postoperative complications: a systematic review and meta-analysis. Ann Surg. 2013;258(6):930-42.

84. Tonnesen H, Rosenberg J, Nielsen HJ, Rasmussen V, Hauge C, Pedersen IK, et al. Effect of preoperative abstinence on poor postoperative outcome in alcohol misusers: randomised controlled trial. BMJ. 1999:318(7194):1311-6.

85. Oppedal K, Møller AM, Pedersen B, Tønnesen H. Preoperative alcohol cessation prior to elective surgery. Cochrane Database Syst Rev. 2012;(7): CD008343.

86. Andersen T, Christensen FB, Laursen M, Hoy K, Hansen ES, Bunger C. Smoking as a predictor of negative outcome in lumbar spinal fusion. Spine (Phila Pa 1976). 2001;26(23):2623-8.

87. Bydon M, De la Garza-Ramos R, Abt NB, Gokaslan ZL, Wolinsky JP, Sciubba $\mathrm{DM}$, et al. Impact of smoking on complication and pseudarthrosis rates after single- and 2-level posterolateral fusion of the lumbar spine. Spine (Phila Pa 1976). 2014;39(21):1765-70.

88. Ali ZS, Ma TS, Ozturk AK, Malhotra NR, Schuster JM, Marcotte PJ, et al. Preoptimization of spinal surgery patients: development of a neurosurgical enhanced recovery after surgery (ERAS) protocol. Clin Neurol Neurosurg. 2018:164:142-53.

89. Glassman SD, Anagnost SC, Parker A, Burke D, Johnson JR, Dimar JR. The effect of cigarette smoking and smoking cessation on spinal fusion. Spine (Phila Pa 1976). 2000;25(20):2608-15.

90. Warner David O, Warltier MD. Perioperative Abstinence from cigarettes: physiologic and clinical consequences. Anesthesiology. 2006;104(2):356-67.

91. Theadom A, Cropley M. Effects of preoperative smoking cessation on the incidence and risk of intraoperative and postoperative complications in adult smokers: a systematic review. Tob Control. 2006;15(5):352-8.

92. Thomsen T, Villebro N, Møller AM. Interventions for preoperative smoking cessation. Cochrane Database Syst Rev. 2014;2014(3):CD002294.

93. Levy N, Dhatariya K. Pre-operative optimisation of the surgical patient with diagnosed and undiagnosed diabetes: a practical review. Anaesthesia. 2019; 74(Suppl 1):58-66.

94. Hughes MJ, Hackney RJ, Lamb PJ, Wigmore SJ, Christopher Deans DA, Skipworth RJE. Prehabilitation before major abdominal surgery: a systematic review and meta-analysis. World J Surg. 2019;43(7):1661-8.

95. Nielsen PR, Jorgensen LD, Dahl B, Pedersen T, Tonnesen H. Prehabilitation and early rehabilitation after spinal surgery: randomized clinical trial. Clin Rehabil. 2010;24(2):137-48.

96. Angus M, Jackson K, Smurthwaite G, Carrasco R, Mohammad S, Verma R, et al. The implementation of enhanced recovery after surgery (ERAS) in complex spinal surgery. J Spine Surg. 2019;5(1):116-23.

97. Nielsen PR, Andreasen J, Asmussen M, Tonnesen H. Costs and quality of life for prehabilitation and early rehabilitation after surgery of the lumbar spine. BMC Health Serv Res. 2008;8:209.

98. Louw A, Diener I, Landers MR, Puentedura EJ. Preoperative pain neuroscience education for lumbar radiculopathy: a multicenter randomized controlled trial with 1-year follow-up. Spine (Phila Pa 1976). 2014:39(18):1449-57.

99. Lindback Y, Tropp H, Enthoven P, Abbott A, Oberg B. PREPARE: presurgery physiotherapy for patients with degenerative lumbar spine disorder: a randomized controlled trial. Spine J. 2018;18(8):1347-55.

100. Gometz A, Maislen D, Youtz C, Kary E, Gometz EL, Sobotka S, et al. The effectiveness of Prehabilitation (prehab) in both functional and economic outcomes following spinal surgery: a systematic review. Cureus. 2018;10(5): e2675.

101. Adogwa O, Martin JR, Huang K, Verla T, Fatemi P, Thompson P, et al. Preoperative serum albumin level as a predictor of postoperative complication after spine fusion. Spine (Phila Pa 1976). 2014;39(18):1513-9.

102. Salvetti DJ, Tempel ZJ, Gandhoke GS, Parry PV, Grandhi RM, Kanter AS, et al. Preoperative prealbumin level as a risk factor for surgical site infection following elective spine surgery. Surg Neurol Int. 2015;6(Suppl 19):S500-3.

103. Salvetti DJ, Tempel ZJ, Goldschmidt E, Colwell NA, Angriman F, Panczykowski DM, et al. Low preoperative serum prealbumin levels and the postoperative surgical site infection risk in elective spine surgery: a consecutive series. J Neurosurg Spine. 2018;29(5):549-52.

104. Fu MC, Buerba RA, Grauer JN. Preoperative nutritional status as an adjunct predictor of major postoperative complications following anterior cervical discectomy and fusion. Clin Spine Surg. 2016;29(4):167-72.

105. Klein JD, Hey LA, Yu CS, Klein BB, Coufal FJ, Young EP, et al. Perioperative nutrition and postoperative complications in patients undergoing spinal surgery. Spine (Phila Pa 1976). 1996;21 (22):2676-82.

106. Drover JW, Dhaliwal R, Weitzel L, Wischmeyer PE, Ochoa JB, Heyland DK. Perioperative use of arginine-supplemented diets: a systematic review of the evidence. J Am Coll Surg. 2011;212(3):385-399, 99 e1.

107. Hegazi RA, Hustead DS, Evans DC. Preoperative standard oral nutrition supplements vs immunonutrition: results of a systematic review and metaanalysis. J Am Coll Surg. 2014;219(5):1078-87.

108. Gupta R, Senagore A. Immunonutrition within enhanced recovery after surgery (ERAS): an unresolved matter. Perioper Med (Lond). 2017;6:24.

109. Musallam KM, Tamim HM, Richards T, Spahn DR, Rosendaal FR, Habbal A, et al. Preoperative anaemia and postoperative outcomes in non-cardiac surgery: a retrospective cohort study. Lancet. 2011;378(9800):1396-407.

110. Kotze A, Carter LA, Scally AJ. Effect of a patient blood management programme on preoperative anaemia, transfusion rate, and outcome after primary hip or knee arthroplasty: a quality improvement cycle. $\mathrm{Br} J$ Anaesth. 2012;108(6):943-52.

111. Fowler AJ, Ahmad T, Phull MK, Allard S, Gillies MA, Pearse RM. Meta-analysis of the association between preoperative anaemia and mortality after surgery. Br J Surg. 2015;102(11):1314-24. 
112. Lasocki S, Krauspe R, Von Heymann C, Mezzacasa A, Chainey S, Spahn DR. PREPARE: the prevalence of perioperative anaemia and need for patient blood management in elective orthopaedic surgery: a multicentre, observational study. Eur J Anaesthesiol. 2015;32(3):160-7.

113. Khanna R, Harris DA, McDevitt JL, Fessler RG, Carabini LM, Lam SK, et al. Impact of Anemia and transfusion on readmission and length of stay after spinal surgery: a single-center study of 1187 operations. Clin Spine Surg. 2017:30(10):E1338-e42.

114. Sanoufa M, Smisson W, Floyd H, Robinson JS. The effect of anaemia on hospital length of stay in lumbar decompression and fusion procedures. J Perioper Pract. 2015;25(12):267-71.

115. Elsamadicy AA, Adogwa O, Vuong VD, Mehta Al, Vasquez RA, Cheng J, et al. Association of Intraoperative Blood Transfusions on postoperative complications, 30-day readmission rates, and 1-year patient-reported outcomes. Spine (Phila Pa 1976). 2017;42(8):610-5.

116. Munoz M, Acheson AG, Auerbach M, Besser M, Habler O, Kehlet $H$, et al. International consensus statement on the peri-operative management of anaemia and iron deficiency. Anaesthesia. 2017;72(2):233-47.

117. Ng O, Keeler BD, Mishra A, Simpson A, Neal K, Brookes MJ, et al. Iron therapy for pre-operative anaemia. Cochrane Database Syst Rev. 2015;12: CD011588.

118. Miles LF, Story DA, Litton E. Peri-operative correction of non-anaemic iron deficiency. Anaesthesia. 2017;72(7):910-1.

119. Litton E, Xiao J, Ho KM. Safety and efficacy of intravenous iron therapy in reducing requirement for allogeneic blood transfusion: systematic review and meta-analysis of randomised clinical trials. Bmj. 2013;347:f4822.

120. Avni T, Bieber A, Grossman A, Green H, Leibovici L, Gafter-Gvili A. The safety of intravenous iron preparations: systematic review and meta-analysis. Mayo Clin Proc. 2015;90(1):12-23

121. Hu SS. Blood loss in adult spinal surgery. Eur Spine J. 2004;13(1):S3-5.

122. Theusinger OM, Spahn DR. Perioperative blood conservation strategies for major spine surgery. Best Pract Res Clin Anaesthesiol. 2016;30(1):41-52.

123. Zhang F, Wang K, Li FN, Huang X, Li Q, Chen Z, et al. Effectiveness of tranexamic acid in reducing blood loss in spinal surgery: a meta-analysis. BMC Musculoskelet Disord. 2014;15:448.

124. Willner D, Spennati V, Stohl S, Tosti G, Aloisio S, Bilotta F. Spine surgery and blood loss: systematic review of clinical evidence. Anesth Analg. 2016;123(5):1307-15.

125. Hui S, Xu D, Ren Z, Chen X, Sheng L, Zhuang Q, et al. Can tranexamic acid conserve blood and save operative time in spinal surgeries? A metaanalysis. Spine J. 2018;18(8):1325-37.

126. Naik BI, Pajewski TN, Bogdonoff DI, Zuo Z, Clark P, Terkawi AS, et al. Rotational thromboelastometry-guided blood product management in major spine surgery. J Neurosurg Spine. 2015;23(2):239-49.

127. Guan J, Cole CD, Schmidt MH, Dailey AT. Utility of intraoperative rotational thromboelastometry in thoracolumbar deformity surgery. J Neurosurg Spine. 2017;27(5):528-33.

128. Buell TJ, Taylor DG, Chen CJ, Dunn LK, Mullin JP, Mazur MD, et al. Rotational thromboelastometry-guided transfusion during lumbar pedicle subtraction osteotomy for adult spinal deformity: preliminary findings from a matched cohort study. Neurosurg Focus. 2019;46(4):E17.

129. Kelly MP, Zebala LP, Kim HJ, Sciubba DM, Smith JS, Shaffrey Cl, et al. Effectiveness of preoperative autologous blood donation for protection against allogeneic blood exposure in adult spinal deformity surgeries: a propensity-matched cohort analysis. J Neurosurg Spine. 2016;24(1):124-30.

130. Solves P, Carpio N, Moscardo F, Bas T, Canigral C, Salazar C, et al. Results of a preoperative autologous blood donation program for patients undergoing elective major spine surgery. Transfus Apher Sci. 2013:49(2):345-8.

131. Choi HY, Hyun SJ, Kim KJ, Jahng TA, Kim HJ. Clinical efficacy of intraoperative cell salvage system in major spinal deformity surgery. J Korean Neurosurg Soc. 2019;62(1):53-60.

132. Carless PA, Henry DA, Moxey AJ, O'Connell D, Brown T, Fergusson DA. Cell salvage for minimising perioperative allogeneic blood transfusion. Cochrane Database Syst Rev. 2010;(3):Cd001888

133. Bowen RE, Gardner S, Scaduto AA, Eagan M, Beckstead J. Efficacy of intraoperative cell salvage systems in pediatric idiopathic scoliosis patients undergoing posterior spinal fusion with segmental spinal instrumentation Spine (Phila Pa 1976). 2010;35(2):246-51.

134. Miao Y-L, Ma H-S, Guo W-Z, Wu J-G, Liu Y, Shi W-Z, et al. The efficacy and cost-effectiveness of cell saver use in instrumented posterior correction and fusion surgery for scoliosis in school-aged children and adolescents. PLoS One. 2014;9(4):e92997.
135. Gause PR, Siska PA, Westrick ER, Zavatsky J, Irrgang JJ, Kang JD. Efficacy of intraoperative cell saver in decreasing postoperative blood transfusions in instrumented posterior lumbar fusion patients. Spine (Phila Pa 1976). 2008; 33(5):571-5.

136. Monk TG, Bronsert MR, Henderson WG, Mangione MP, Sum-Ping ST, Bentt $\mathrm{DR}$, et al. Association between intraoperative hypotension and hypertension and 30-day postoperative mortality in noncardiac surgery. Anesthesiology. 2015;123(2):307-19.

137. Tran S, Wolever TM, Errett LE, Ahn H, Mazer CD, Keith M. Preoperative carbohydrate loading in patients undergoing coronary artery bypass or spinal surgery. Anesth Analg. 2013;117(2):305-13.

138. Smith MD, McCall J, Plank L, Herbison GP, Soop M, Nygren J. Preoperative carbohydrate treatment for enhancing recovery after elective surgery. Cochrane Database Syst Rev. 2014;(8):CD009161

139. Brady MC, Kinn S, Stuart $P$, Ness V. Preoperative fasting for adults to prevent perioperative complications. Cochrane Database Syst Rev. 2003;(4):CD0044223.

140. Smith I, Kranke P, Murat I, Smith A, O'Sullivan G, Soreide E, et al. Perioperative fasting in adults and children: guidelines from the European Society of Anaesthesiology. Eur J Anaesthesiol. 2011;28(8):556-69.

141. Awad S, Varadhan KK, Ljungqvist O, Lobo DN. A meta-analysis of randomised controlled trials on preoperative oral carbohydrate treatment in elective surgery. Clin Nutr. 2013;32(1):34-44.

142. Sinha A, Jayaraman L, Punhani D, Chowbey P. Enhanced recovery after bariatric surgery in the severely obese, morbidly obese, super-morbidly obese and super-super morbidly obese using evidence-based clinical pathways: a comparative study. Obes Surg. 2017;27(3):560-8.

143. Turan A, Karamanlioglu B, Memis D, Hamamcioglu MK, Tukenmez B, Pamukcu Z, et al. Analgesic effects of gabapentin after spinal surgery. Anesthesiology. 2004;100(4):935-8.

144. Pandey CK, Navkar DV, Giri PJ, Raza M, Behari S, Singh RB, et al. Evaluation of the optimal preemptive dose of gabapentin for postoperative pain relief after lumbar diskectomy: a randomized, double-blind, placebo-controlled study. J Neurosurg Anesthesiol. 2005;17(2):65-8.

145. Yu L, Ran B, Li M, Shi Z. Gabapentin and pregabalin in the management of postoperative pain after lumbar spinal surgery: a systematic review and meta-analysis. Spine (Phila Pa 1976). 2013:38(22):1947-52.

146. Ozgencil E, Yalcin S, Tuna H, Yorukoglu D, Kecik Y. Perioperative administration of gabapentin 1,200 mg day-1 and pregabalin $300 \mathrm{mg}$ day-1 for pain following lumbar laminectomy and discectomy: a randomised, doubleblinded, placebo-controlled study. Singapore Med J. 2011;52(12):883-9.

147. Raja SD, Shetty AP, Subramanian B, Kanna RM, Rajasekaran S. A prospective randomized study to analyze the efficacy of balanced pre-emptive analgesia in spine surgery. Spine J. 2018;19(4):569-77.

148. Lee BH, Park JO, Suk KS, Kim TH, Lee HM, Park MS, et al. Pre-emptive and multi-modal perioperative pain management may improve quality of life in patients undergoing spinal surgery. Pain Physician. 2013;16(3):E217-26.

149. Siribumrungwong K, Cheewakidakarn J, Tangtrakulwanich B, Nimmaanrat S. Comparing parecoxib and ketorolac as preemptive analgesia in patients undergoing posterior lumbar spinal fusion: a prospective randomized doubleblinded placebo-controlled trial. BMC Musculoskelet Disord. 2015;16:59.

150. Aglio L, Kim G, Zhou J, Gugino L, Crossley L. Pre-emptive analgesia for postperative pain relief in thoraco-lumbo-sacral spine surgeries: a doubleblinded randomized control trial. J Neurosurg Anesthesiol. 2015;27(4):428.

151. Gan TJ, Diemunsch P, Habib AS, Kovac A, Kranke P, Meyer TA, et al. Consensus guidelines for the management of postoperative nausea and vomiting. Anesth Analg. 2014;118(1):85-113.

152. Kaye AD, Urman RD, Rappaport $Y$, Siddaiah $H$, Cornett EM, Belani $K$, et al. Multimodal analgesia as an essential part of enhanced recovery protocols in the ambulatory settings. J Anaesthesiol Clin Pharmacol. 2019:35(Suppl 1):S40-s5.

153. Elia N, Lysakowski C, Tramer MR. Does multimodal analgesia with acetaminophen, nonsteroidal antiinflammatory drugs, or selective cyclooxygenase- 2 inhibitors and patient-controlled analgesia morphine offer advantages over morphine alone? Meta-analyses of randomized trials. Anesthesiology. 2005;103(6):1296-304.

154. McClell S, Takemoto RC, Lonner BS, Andres TM, Park JJ, Ricart-Hoffiz PA, et al. Analysis of postoperative thoracolumbar spine infections in a prospective randomized controlled trial using the centers for disease control surgical site infection criteria. Int J Spine Surg. 2016;10(2016) (no pagination).

155. Savage JW, Weatherford BM, Sugrue PA, Nolden MT, Liu JC, Song JK, et al. Efficacy of surgical preparation solutions in lumbar spine surgery. J Bone Joint Surg (Am Vol). 2012;94(6):490-4. 
156. Ghobrial GM, Wang MY, Green BA, Levene HB, Manzano G, Vanni S, et al. Preoperative skin antisepsis with chlorhexidine gluconate versus povidoneiodine: a prospective analysis of 6959 consecutive spinal surgery patients. J Neurosurg Spine. 2018;28(2):209-14.

157. Edmiston CE Jr, Bruden B, Rucinski MC, Henen C, Graham MB, Lewis BL. Reducing the risk of surgical site infections: does chlorhexidine gluconate provide a risk reduction benefit? Am J Infect Control. 2013;41(5 Suppl):S49-55.

158. Patrick S, McDowell A, Lee A, Frau A, Martin U, Gardner E, et al. Antisepsis of the skin before spinal surgery with povidone iodine-alcohol followed by chlorhexidine gluconate-alcohol versus povidone iodine-alcohol applied twice for the prevention of contamination of the wound by bacteria: a randomised controlled trial. Bone Joint J. 2017;99-b(10):1354-65.

159. Sidhwa F, Itani KM. Skin preparation before surgery: options and evidence. Surg Infect (Larchmt). 2015;16(1):14-23.

160. Olsen MA, Nepple JJ, Riew KD, Lenke LG, Bridwell KH, Mayfield J, et al. Risk factors for surgical site infection following orthopaedic spinal operations. J Bone Joint Surg Am. 2008;90(1):62-9.

161. Pull ter Gunne AF, Cohen DB. Incidence, prevalence, and analysis of risk factors for surgical site infection following adult spinal surgery. Spine (Phila Pa 1976). 2009;34(13):1422-8.

162. Bratzler DW, Dellinger EP, Olsen KM, Perl TM, Auwaerter PG, Bolon MK, et al. Clinical practice guidelines for antimicrobial prophylaxis in surgery. Surg Infect (Larchmt). 2013;14(1):73-156.

163. Barker FG, 2nd. Efficacy of prophylactic antibiotic therapy in spinal surgery: a meta-analysis. Neurosurgery. 2002;51(2):391-400; discussion -1.

164. Epstein NE. Preoperative, intraoperative, and postoperative measures to further reduce spinal infections. Surg Neurol Int. 2011;2:17.

165. Bakhsheshian J, Dahdaleh NS, Lam SK, Savage JW, Smith ZA. The use of vancomycin powder in modern spine surgery: systematic review and metaanalysis of the clinical evidence. World Neurosurg. 2015;83(5):816-23.

166. Hill BW, Emohare O, Song B, Davis R, Kang MM. The use of vancomycin powder reduces surgical reoperation in posterior instrumented and noninstrumented spinal surgery. Acta Neurochir. 2014;156(4):749-54.

167. Gande A, Rosinski A, Cunningham T, Bhatia N, Lee YP. Selection pressures of vancomycin powder use in spine surgery: a meta-analysis. Spine J. 2019; 19(6):1076-84

168. Grabel ZJ, Boden A, Segal DN, Boden S, Milby AH, Heller JG. The impact of prophylactic intraoperative vancomycin powder on microbial profile, antibiotic regimen, length of stay, and reoperation rate in elective spine surgery. Spine J. 2019;19(2):261-6.

169. Park HY, Sheppard W, Smith R, Xiao J, Gatto J, Bowen R, et al. The combined administration of vancomycin IV, standard prophylactic antibiotics, and vancomycin powder in spinal instrumentation surgery: does the routine use affect infection rates and bacterial resistance? J Spine Surg. 2018;4(2):173-9.

170. Steel T, Jones R, Crossman J, Sheehy J, Bentivoglio P, Pell M. Intraoperative wound infiltration with bupivacaine in patients undergoing lumbar spine surgery. J Clin Neurosci. 1998:5(3):298-303.

171. Gurbet A, Bekar A, Bilgin H, Korfali G, Yilmazlar S, Tercan M. Pre-emptive infiltration of levobupivacaine is superior to at-closure administration in lumbar laminectomy patients. Eur Spine J. 2008;17(9):1237-41.

172. Ersayli DT, Gurbet A, Bekar A, Uckunkaya N, Bilgin H. Effects of perioperatively administered bupivacaine and bupivacainemethylprednisolone on pain after lumbar discectomy. Spine (Phila Pa 1976). 2006;31(19):2221-6.

173. Chadduck JB, Sneyd JR, Pobereskin LH. The role of bupivacaine in early postoperative pain control after lumbar decompression. J Neurosurg. 1999; 90(1 Suppl):67-72

174. Kjaergaard M, Moiniche S, Olsen KS. Wound infiltration with local anesthetics for post-operative pain relief in lumbar spine surgery: a systematic review. Acta Anaesthesiol Scand. 2012;56(3):282-90.

175. Schraag S, Pradelli L, Alsaleh AJO, Bellone M, Ghetti G, Chung TL, et al. Propofol vs. inhalational agents to maintain general anaesthesia in ambulatory and in-patient surgery: a systematic review and meta-analysis. BMC Anesthesiol. 2018;18(1):162.

176. Kumar G, Stendall C, Mistry R, Gurusamy K, Walker D. A comparison of total intravenous anaesthesia using propofol with sevoflurane or desflurane in ambulatory surgery: systematic review and meta-analysis. Anaesthesia. 2014; 69(10):1138-50.

177. Mishra L, Pradhan S, Pradhan C. Comparison of propofol based anaesthesia to conventional inhalational general anaesthesia for spine surgery. J Anaesthesiol Clin Pharmacol. 2011;27(1):59-61.
178. Lin WL, Lee MS, Wong CS, Chan SM, Lai HC, Wu ZF, et al. Effects of intraoperative propofol-based total intravenous anesthesia on postoperative pain in spine surgery: comparison with desflurane anesthesia - a randomised trial. Medicine. 2019;98(13):e15074.

179. Konstantopoulos K, Makris A, Moustaka A, Karmaniolou I, Konstantopoulos G, Mela A. Sevoflurane versus propofol anesthesia in patients undergoing lumbar spondylodesis: a randomized trial. J Surg Res. 2013;179(1):72-7.

180. Angst MS. Intraoperative use of remifentanil for TIVA: postoperative pain, acute tolerance, and opioid-induced hyperalgesia. J Cardiothorac Vasc Anesth. 2015;29(Suppl 1):S16-22.

181. Yeom JH, Kim KH, Chon MS, Byun J, Cho SY. Remifentanil used as adjuvant in general anesthesia for spinal fusion does not exhibit acute opioid tolerance. Korean J Anesthesiol. 2012:63(2):103-7.

182. Crawford MW, Hickey C, Zaarour C, Howard A, Naser B. Development of acute opioid tolerance during infusion of remifentanil for pediatric scoliosis surgery. Anesth Analg. 2006;102(6):1662-7.

183. MacDonald DB, Dong C, Quatrale R, Sala F, Skinner S, Soto F, et al. Recommendations of the International Society of Intraoperative Neurophysiology for intraoperative somatosensory evoked potentials. Clin Neurophysiol. 2019;130(1):161-79.

184. Tender G. Minimally invasive spine SUrgery techniques. Switzerland: Springer Nature Switzerland AG; 2018.

185. Soffin EM, Vaishnav AS, Wetmore D, Barber L, Hill P, Gang CH, et al. Design and Implementation of an Enhanced Recovery After Surgery (ERAS) Program for Minimally Invasive Lumbar Decompression Spine Surgery: Initial Experience. Spine (Phila Pa 1976). 2019;44(9):E561-70.

186. Wang MY, Grossman J. Endoscopic minimally invasive transforaminal interbody fusion without general anesthesia: initial clinical experience with 1-year follow-up. Neurosurg Focus. 2016;40(2):E13.

187. Grasu RM, Cata JP, Dang AQ, Tatsui CE, Rhines LD, Hagan KB, et al. Implementation of an enhanced recovery after spine surgery program at a large cancer center: a preliminary analysis. J Neurosurg Spine. 2018;29(5): 588-98.

188. Seng C, Siddiqui M, Wong K, Zhang K, Yeo W, Tan S, et al. Five-year outcomes of minimally invasive versus open transforaminal lumbar interbody fusion: a matched-pair comparison study. Spine (Phila Pa 1976). 2013;38:2049-55.

189. Goldstein CL, Macwan K, Sundararajan K, Rampersaud YR. Perioperative outcomes and adverse events of minimally invasive versus open posterior lumbar fusion: meta-analysis and systematic review. J Neurosurg Spine. 2016:24(3):416-27.

190. Adogwa O, Carr K, Thompson P, Hoang K, Darlington T, Perez E, et al. A prospective, multi-institutional comparative effectiveness study of lumbar spine surgery in morbidly obese patients: does minimally invasive transforaminal lumbar interbody fusion result in superior outcomes? World Neurosurg. 2015;83(5):860-6.

191. Senker W, Gruber A, Gmeiner M, Stefanits H, Sander K, Rössler P, et al. Surgical and clinical results of minimally invasive spinal fusion surgery in an unselected patient cohort of a spinal care unit. Orthop Surg. 2018;10(3):192-7.

192. Rajagopalan S, Mascha E, Na J, Sessler Daniel I. The effects of mild perioperative hypothermia on blood loss and transfusion requirement. Anesthesiology 2008;108(1):71-7.

193. Frank SM, Fleisher LA, Breslow MJ, Higgins MS, Olson KF, Kelly S, et al. Perioperative maintenance of normothermia reduces the incidence of morbid cardiac events. A randomized clinical trial. JAMA. 1997;277(14):1127-34.

194. Plummer M, Leary RO. Spinal cord injury. In: Gelb A, Gupta A, Duane D, Adapa $R$, editors. Gupta and Gelb's essentials of Neuroanesthesia and Neurointensive care. 2nd ed. Cambridge: Cambridge University Press; 2018. p. 231-8.

195. Kwon BK, Mann C, Sohn HM, Hilibrand AS, Phillips FM, Wang JC, et al. Hypothermia for spinal cord injury. Spine J. 2008;8(6):859-74.

196. Gorges M, West NC, Cheung W, Zhou G, Miyanji F, Whyte SD. Preoperative warming and undesired surgical and anesthesia outcomes in pediatric spinal surgery-a retrospective cohort study. Paediatr Anaesth. 2016;26(9):866-75.

197. Oh TK, Ryu JH, Sohn HM, Jeon YT. Intraoperative hypothermia is associated with reduced acute kidney injury after spine surgery under general anesthesia: a retrospective observational study. J Neurosurg Anesthesiol. 2018;32(1):63-9.

198. Makaryus R, Miller TE, Gan TJ. Current concepts of fluid management in enhanced recovery pathways. Br J Anaesth. 2018;120(2):376-83.

199. Corcoran T, Emma Joy Rhodes J, Clarke S, Myles PS, Ho KM. Perioperative fluid management strategies in major surgery: a stratified meta-analysis. Anesth Analg. 2012;114(3):640-51. 
200. Grocott MP, Dushianthan A, Hamilton MA, Mythen MG, Harrison D, Rowan K. Perioperative increase in global blood flow to explicit defined goals and outcomes following surgery. Cochrane Database Syst Rev. 2012;11: Cd004082.

201. Bacchin MR, Ceria CM, Giannone S, Ghisi D, Stagni G, Greggi T, et al. Goaldirected fluid therapy based on stroke volume variation in patients undergoing major spine surgery in the prone position: a cohort study. Spine (Phila Pa 1976). 2016:41(18):E1131-7.

202. Siemionow K, Cywinski J, Kusza K, Lieberman I. Intraoperative fluid therapy and pulmonary complications. Orthopedics. 2012;35(2):e184-91.

203. Devin CJ, McGirt MJ. Best evidence in multimodal pain management in spine surgery and means of assessing postoperative pain and functional outcomes. J Clin Neurosci. 2015;22(6):930-8.

204. Zhang Z, Xu H, Zhang Y, Li W, Yang Y, Han T, et al. Nonsteroidal antiinflammatory drugs for postoperative pain control after lumbar spine surgery: a meta-analysis of randomized controlled trials. J Clin Anesth. 2017;43:84-9.

205. Jirarattanaphochai K, Jung S. Nonsteroidal antiinflammatory drugs for postoperative pain management after lumbar spine surgery: a meta-analysis of randomized controlled trials. J Neurosurg Spine. 2008:9(1):22-31.

206. Dodwell ER, Latorre JG, Parisini E, Zwettler E, Chandra D, Mulpuri K, et al. NSAID exposure and risk of nonunion: a meta-analysis of case-control and cohort studies. Calcif Tissue Int. 2010;87(3):193-202.

207. Li Q, Zhang Z, Cai Z. High-dose ketorolac affects adult spinal fusion: a metaanalysis of the effect of perioperative nonsteroidal anti-inflammatory drugs on spinal fusion. Spine (Phila Pa 1976). 2011;36(7):E461-8.

208. Urban MK, Ya Deau JT, Wukovits B, Lipnitsky JY. Ketamine as an adjunct to postoperative pain management in opioid tolerant patients after spinal fusions: a prospective randomized trial. HSS J. 2008;4(1):62-5.

209. Loftus RW, Yeager MP, Clark JA, Brown JR, Abdu WA, Sengupta DK, et al. Intraoperative ketamine reduces perioperative opiate consumption in opiate-dependent patients with chronic back pain undergoing back surgery. Anesthesiology. 2010;113(3):639-46.

210. Song JW, Shim JK, Song Y, Yang SY, Park SJ, Kwak YL. Effect of ketamine as an adjunct to intravenous patient-controlled analgesia, in patients at high risk of postoperative nausea and vomiting undergoing lumbar spinal surgery. Br J Anaesth. 2013;111(4):630-5.

211. Pendi A, Field R, Farhan SD, Eichler M, Bederman SS. Perioperative ketamine for analgesia in spine surgery: a meta-analysis of randomized controlled trials. Spine (Phila Pa 1976). 2018;43(5):E299-e307.

212. Subramaniam K, Akhouri V, Glazer PA, Rachlin J, Kunze L, Cronin M, et al. Intra- and postoperative very low dose intravenous ketamine infusion does not increase pain relief after major spine surgery in patients with preoperative narcotic analgesic intake. Pain Med. 2011;12(8):1276-83.

213. Gottschalk A, Durieux ME, Nemergut EC. Intraoperative methadone improves postoperative pain control in patients undergoing complex spine surgery. Anesth Analg. 2011;112(1):218-23.

214. Oguzhan N, Gunday I, Turan A. Effect of magnesium sulfate infusion on sevoflurane consumption, hemodynamics, and perioperative opioid consumption in lumbar disc surgery. J Opioid Manag. 2008;4(2):105-10.

215. Levaux C, Bonhomme V, Dewandre PY, Brichant JF, Hans P. Effect of intraoperative magnesium sulphate on pain relief and patient comfort after major lumbar orthopaedic surgery. Anaesthesia. 2003;58(2):131-5.

216. Garg N, Panda NB, Gandhi KA, Bhagat H, Batra YK, Grover VK, et al. Comparison of small dose ketamine and Dexmedetomidine infusion for postoperative analgesia in spine surgery--a prospective randomized doubleblind placebo controlled study. J Neurosurg Anesthesiol. 2016;28(1):27-31.

217. Khurana G, Jindal P, Sharma JP, Bansal KK. Postoperative pain and long-term functional outcome after administration of gabapentin and pregabalin in patients undergoing spinal surgery. Spine (Phila Pa 1976). 2014;39(6):E363-8.

218. Farag E, Ghobrial M, Sessler DI, Dalton JE, Liu J, Lee JH, et al. Effect of perioperative intravenous lidocaine administration on pain, opioid consumption, and quality of life after complex spine surgery. Anesthesiology. 2013;119(4):932-40

219. Ibrahim A, Aly M, Farrag W. Effect of intravenous lidocaine infusion on long-term postoperative pain after spinal fusion surgery. Medicine. 2018;97(13):e0229.

220. Kim KT, Cho DC, Sung JK, Kim YB, Kang H, Song KS, et al. Intraoperative systemic infusion of lidocaine reduces postoperative pain after lumbar surgery: a double-blinded, randomized, placebo-controlled clinical trial. Spine J. 2014;14(8):1559-66.

221. Batko I, Kościelniak-Merak B, Tomasik PJ, Kobylarz K, Wordliczek J. Lidocaine as an element of multimodal analgesic therapy in major spine surgical procedures in children: a prospective, randomized, double-blind study. Pharmacol Rep. 2020;72(3):744-55.

222. Dewinter G, Moens P, Fieuws S, Vanaudenaerde B, Van de Velde M, Rex S. Systemic lidocaine fails to improve postoperative morphine consumption, postoperative recovery and quality of life in patients undergoing posterior spinal arthrodesis. A double-blind, randomized, placebo-controlled trial. Br J Anaesth. 2017;118(4):576-85

223. Prasartritha T, Kunakornsawat $S$, Tungsiripat $R$, Jampa J, Throngnumchai R. A prospective randomized trial comparing epidural morphine through intraoperatively placed epidural catheter and intravenous morphine in major lumbar spinal surgery. J Spinal Disord Tech. 2010;23(8):e43-6.

224. Milbrandt TA, Singhal M, Minter C, McClung A, Talwalkar VR, Iwinski HJ, et al. A comparison of three methods of pain control for posterior spinal fusions in adolescent idiopathic scoliosis. Spine (Phila Pa 1976). 2009;34(14):1499-503.

225. Urban MK, Jules-Elysee K, Urquhart B, Cammisa FP, Boachie-Adjei O. Reduction in postoperative pain after spinal fusion with instrumentation using intrathecal morphine. Spine (Phila Pa 1976). 2002:27(5):535-7.

226. Yen D, Turner $K$, Mark D. Is a single low dose of intrathecal morphine a useful adjunct to patient-controlled analgesia for postoperative pain control following lumbar spine surgery? A preliminary report. Pain Res Manag. 2015; 20(3):129-32.

227. Boezaart AP, Eksteen JA, Spuy GV, Rossouw P, Knipe M. Intrathecal morphine. Double-blind evaluation of optimal dosage for analgesia after major lumbar spinal surgery. Spine (Phila Pa 1976). 1999;24(11):1131-7.

228. Ziegeler S, Fritsch E, Bauer C, Mencke T, Muller BI, Soltesz S, et al. Therapeutic effect of intrathecal morphine after posterior lumbar interbody fusion surgery: a prospective, double-blind, randomized study. Spine (Phila Pa 1976). 2008:33(22):2379-86.

229. Tripi PA, Poe-Kochert C, Potzman J, Son-Hing JP, Thompson GH. Intrathecal morphine for postoperative analgesia in patients with idiopathic scoliosis undergoing posterior spinal fusion. Spine (Phila Pa 1976). 2008;33(20):2248-51.

230. France JC, Jorgenson SS, Lowe TG, Dwyer AP. The use of intrathecal morphine for analgesia after posterolateral lumbar fusion: a prospective, double-blind, randomized study. Spine (Phila Pa 1976). 1997;22(19):2272-7.

231. Pendi A, Acosta FL, Tuchman A, Movahedi R, Sivasundaram L, Arif I, et al. Intrathecal morphine in spine surgery: a meta-analysis of randomized controlled trials. Spine (Phila Pa 1976). 2017;42(12):E740-e7.

232. Lamperti M, Tufegdzic $B$, Avitsian R. Management of complex spine surgery. Curr Opin Anesthesiol. 2017;30(5):551-6.

233. Muhly WT, Sankar WN, Ryan K, Norton A, Maxwell LG, DiMaggio T, et al. Rapid Recovery Pathway After Spinal Fusion for Idiopathic Scoliosis. Pediatrics. 2016;137(4):e20151568.

234. Mathiesen O, Dahl B, Thomsen BA, Kitter B, Sonne N, Dahl JB, et al. A comprehensive multimodal pain treatment reduces opioid consumption after multilevel spine surgery. Eur Spine J. 2013;22(9):2089-96.

235. Rajpal S, Gordon DB, Pellino TA, Strayer AL, Brost D, Trost GR, et al. Comparison of perioperative oral multimodal analgesia versus IV PCA for spine surgery. J Spinal Disord Tech. 2010;23(2):139-45.

236. Singh K, Bohl DD, Ahn J, Massel DH, Mayo BC, Narain AS, et al. Multimodal analgesia versus intravenous patient-controlled analgesia for minimally invasive Transforaminal lumbar interbody fusion procedures. Spine (Phila Pa 1976). 2017:42(15):1145-50.

237. Bohl DD, Louie PK, Shah N, Mayo BC, Ahn J, Kim TD, et al. Multimodal Versus Patient-Controlled Analgesia After an Anterior Cervical Decompression and Fusion. Spine. 2016:41(12):994-8.

238. Maheshwari K, Avitsian R, Sessler DI, Makarova N, Tanios M, Raza S, et al. Multimodal analgesic regimen for spine surgery: a randomized placebocontrolled trial. Anesthesiology. 2020;132(5):992-1002.

239. Soffin EM, Wetmore DS, Beckman JD, Sheha ED, Vaishnav AS, Albert TJ, et al. Opioid-free anesthesia within an enhanced recovery after surgery pathway for minimally invasive lumbar spine surgery: a retrospective matched cohort study. Neurosurg Focus. 2019;46(4):E8.

240. Kakkos SK, Caprini JA, Geroulakos G, Nicolaides AN, Stansby G, Reddy DJ, et al. Combined intermittent pneumatic leg compression and pharmacological prophylaxis for prevention of venous thromboembolism. Cochrane Database Syst Rev. 2016;9:Cd005258.

241. Mosenthal WP, Landy DC, Boyajian HH, Idowu OA, Shi LL, Ramos E, et al. Thromboprophylaxis in spinal surgery. Spine (Phila Pa 1976). 2018:43(8): E474-e81.

242. Bryson DJ, Uzoigwe CE, Braybrooke J. Thromboprophylaxis in spinal surgery: a survey. J Orthopaed Surg Res. 2012;7:14. 
243. Meddings J, Rogers MA, Krein SL, Fakih MG, Olmsted RN, Saint S. Reducing unnecessary urinary catheter use and other strategies to prevent catheterassociated urinary tract infection: an integrative review. BMJ Qual Saf. 2014; 23(4):277-89.

244. Djordjevic Z, Jankovic S, Gajovic O, Djonovic N, Folic N, Bukumiric Z. Hospital infections in a neurological intensive care unit: incidence, causative agents and risk factors. J Infect Dev Ctries. 2012;6(11):798-805.

245. Aiyer SN, Kumar A, Shetty AP, Kanna RM, Rajasekaran S. Factors influencing postoperative urinary retention following elective posterior lumbar spine surgery: a prospective study. Asian Spine J. 2018;12(6):1100-5.

246. Lee S, Kim CH, Chung CK, Park SB, Yang SH, Kim SH, et al. Risk factor analysis for postoperative urinary retention after surgery for degenerative lumbar spinal stenosis. Spine J. 2017;17(4):469-77.

247. Altschul D, Kobets A, Nakhla J, Jada A, Nasser R, Kinon MD, et al. Postoperative urinary retention in patients undergoing elective spinal surgery. J Neurosurg Spine. 2017;26(2):229-34.

248. Sivaganesan A, Wick JB, Chotai S, Cherkesky C, Stephens BF, Devin CJ. Perioperative protocol for elective spine surgery is associated with reduced length of stay and complications. J Am Acad Orthop Surg. 2019;27(5):183-9.

249. Fletcher ND, Shourbaji N, Mitchell PM, Oswald TS, Devito DP, Bruce RW. Clinical and economic implications of early discharge following posterior spinal fusion for adolescent idiopathic scoliosis. J Child Orthop. 2014;8(3): 257-63

250. Myles PS, Bellomo R, Corcoran T, Forbes A, Peyton P, Story D, et al. Restrictive versus Liberal fluid therapy for major abdominal surgery. N Engl J Med. 2018;378(24):2263-74.

251. Kotagal M, Symons RG, Hirsch IB, Umpierrez GE, Dellinger EP, Farrokhi ET, et al. Perioperative hyperglycemia and risk of adverse events among patients with and without diabetes. Ann Surg. 2015;261(1):97-103.

252. Anderson PA, Savage JW, Vaccaro AR, Radcliff K, Arnold PM, Lawrence BD, et al. Prevention of surgical site infection in spine surgery. Neurosurgery. 2017;80(3S):S114-S23.

253. Lipshutz AK, Gropper MA. Perioperative glycemic control: an evidencebased review. Anesthesiology. 2009;110(2):408-21.

254. Kehlet H, Wilmore DW. Multimodal strategies to improve surgical outcome. Am J Surg. 2002;183(6):630-41.

255. Gornitzky AL, Flynn JM, Muhly WT, Sankar WN. A rapid recovery pathway for adolescent idiopathic scoliosis that improves pain control and reduces time to inpatient recovery after posterior spinal fusion. Spine Deform. 2016;4(4): 288-95.

256. Bradywood A, Farrokhi F, Williams B, Kowalczyk M, Blackmore CC. Reduction of inpatient hospital length of stay in lumbar fusion patients with implementation of an evidence-based clinical care pathway. Spine (Phila Pa 1976). 2017;42(3):169-76.

257. Grant MC, Yang D, Wu CL, Makary MA, Wick EC. Impact of enhanced recovery after surgery and fast track surgery pathways on healthcareassociated infections: results from a systematic review and meta-analysis. Ann Surg. 2017;265(1):68-79.

258. Wu FY. Influence of rehabilitation education on behavior and lumbar functional exercise in patients following operation for lumbar spinal stenosis. Chin J Clin Rehab. 2005;9(26):20-2.

259. Burgess LC, Wainwright TW. What is the evidence for early mobilisation in elective spine surgery? A narrative review. Healthcare (Basel, Switzerland). 2019:7(3):92.

260. Ivers N, Jamtvedt G, Flottorp S, Young JM, Odgaard-Jensen J, French SD, et al. Audit and feedback: effects on professional practice and healthcare outcomes. Cochrane Database Syst Rev. 2012;6:CD000259.

261. The Impact of Enhanced Recovery Protocol Compliance on Elective Colorectal Cancer Resection: Results From an International Registry. Ann Surg. 2015;261(6):1153-9

262. Li L, Jin J, Min S, Liu D, Liu L. Compliance with the enhanced recovery after surgery protocol and prognosis after colorectal cancer surgery: a prospective cohort study. Oncotarget. 2017;8(32):53531-41.

263. Gustafsson UO, Hausel J, Thorell A, Ljungqvist O, Soop M, Nygren J, et al. Adherence to the enhanced recovery after surgery protocol and outcomes after colorectal cancer surgery. Arch Surg. 2011;146(5):571-7.

264. Rogers LJ, Bleetman D, Messenger DE, Joshi NA, Wood L, Rasburn NJ, et al. The impact of enhanced recovery after surgery (ERAS) protocol compliance on morbidity from resection for primary lung cancer. J Thorac Cardiovasc Surg. 2018;155(4):1843-52.
265. Brown JK, Singh K, Dumitru R, Chan E, Kim MP. The benefits of enhanced recovery after surgery programs and their application in cardiothoracic surgery. Methodist Debakey Cardiovasc J. 2018;14(2):77-88.

266. Paton F, Chambers D, Wilson P, Eastwood A, Craig D, Fox D, et al. Effectiveness and implementation of enhanced recovery after surgery programmes: a rapid evidence synthesis. BMJ Open. 2014:4(7):e005015.

267. Guyatt GH, Oxman AD, Vist G, Kunz R, Brozek J, Alonso-Coello P, et al. GRADE guidelines: 4. Rating the quality of evidence--study limitations (risk of bias). J Clin Epidemiol. 2011;64(4):407-15.

\section{Publisher's Note}

Springer Nature remains neutral with regard to jurisdictional claims in published maps and institutional affiliations.
Ready to submit your research? Choose BMC and benefit from:

- fast, convenient online submission

- thorough peer review by experienced researchers in your field

- rapid publication on acceptance

- support for research data, including large and complex data types

- gold Open Access which fosters wider collaboration and increased citations

- maximum visibility for your research: over $100 \mathrm{M}$ website views per year

At $\mathrm{BMC}$, research is always in progress.

Learn more biomedcentral.com/submissions 